\title{
A Study on Increasing Positive Behaviors Using Positive Reinforcement Techniques
}

\author{
Vivetha Gunaretnam \\ (Dip. Counselling, BSW (hons), MSW (c), Sri Lanka) \\ National Institute of Social Development, Sri Lanka
}

\begin{abstract}
Positive reinforcement works by presenting a motivating/reinforcing stimulus to the person after the desired behavior is exhibited, making the behavior more likely to happen in the future. Classroom management is one of the most common problems facing by teachers because disruptive students take up valuable learning time. Students with disruptive, defiant, and disrespectful behaviors often make it difficult for teachers to teach and students to learn. The techniques based on positive reinforcement lack popular and professional acceptability because they are time-intensive, offer little compensation for educators, contradict popular views of developmental psychology, threaten special interest groups, are socially unacceptable, and demean humans. To investigate more on this area, the researcher identified positive reinforcement techniques applied by school teachers on primary students, the effectiveness of the reinforcement techniques for reward, and identified social work interventions to promote positive reinforcement. To conduct this study the researcher selected the Manmunai North zone from Batticaloa, Sri Lanka. This research study was explored through a mixed-method and sequential explanatory research design. The tools such as interview schedule and questionnaire were used to collect data. The collected data were analyzed through SPSS software and thematic analysis. The researcher was able to find the techniques under sensory, natural, material, generalized and social reinforcements. From the techniques most of the teachers agreed with positive reinforcement techniques from sensory, natural, material, generalized and social reinforcements, increase the desirable behavior high in the academic performances except two techniques from generalized reinforcement. The researcher found that the issues in promoting positive reinforcement techniques through the individual level, group level system level, and the social work interventions also found under in mentioned levels. From the overall findings, the researcher can able to induct a hybrid mixture of the explanatory model from the combination of reinforcement model and social interaction model in Social Work Practice.
\end{abstract}

Key words: Positive reinforcement, techniques, school teachers, primary students

\section{INTRODUCTION}

$\mathrm{I}$ n our everyday living, it is important to realize that our behaviors play a major part in assisting us to act and behave in different settings such as at home, school, workplace, and society. Good behaviors can lead to better lives, high achievements in related fields, and good relationships with others. On the other hand, individuals that have bad behaviors might have some unfavourable outcomes in their lives.
However, these inappropriate behaviors can be replaced with desirable behaviors using behavior modification techniques. Many principles can be applied in encouraging and increasing a target's good behaviors that include reinforcements, token economy, punishment, extinction, and classical conditioning. Many kinds of research have shown that positive reinforcements are proven to be more effective in practice as compared to other principles which have some flaws when applying in certain settings. Therefore this research aims to investigate the positive reinforcement techniques applied by school teachers on school-going students in primary unit special reference from Batticaloa District. The following chart shows the conceptual framework of this study.

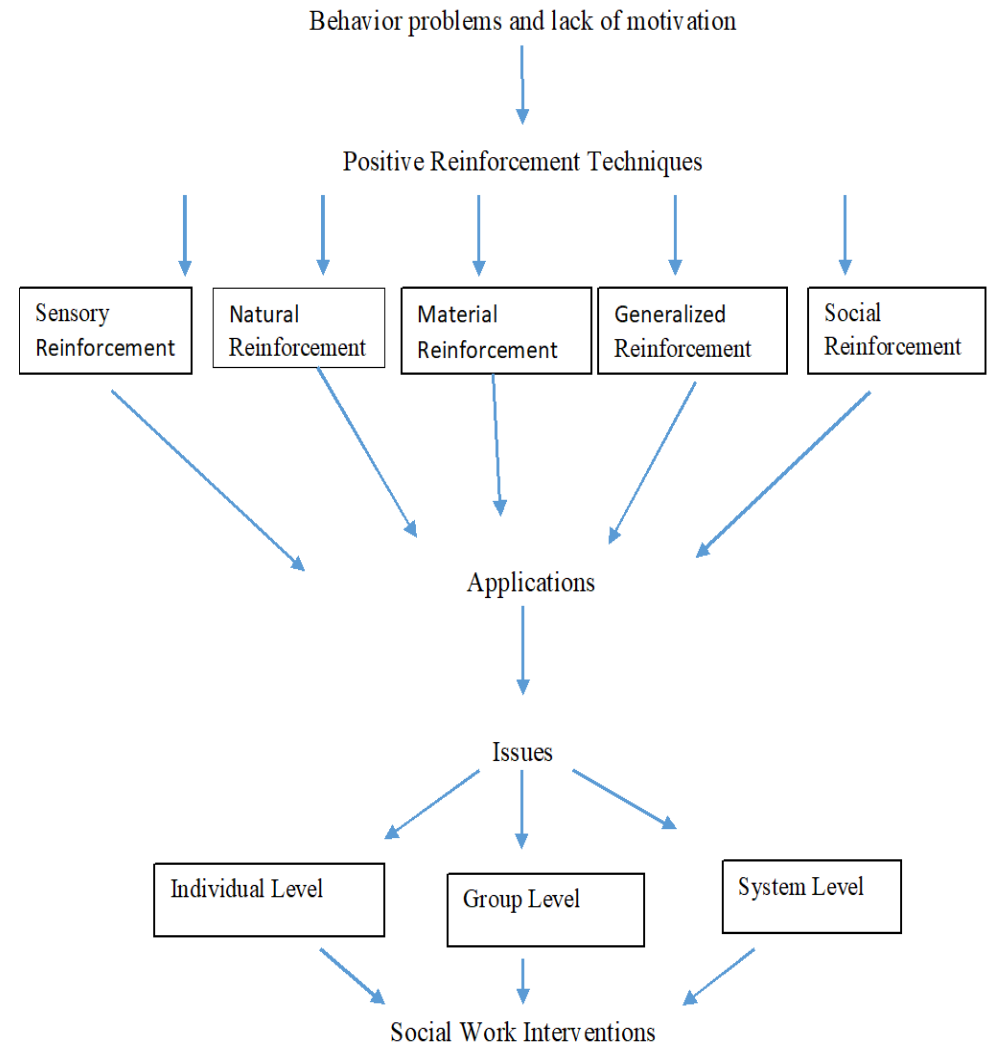

\section{RESEARCH METHODOLOGY}

In this study, the mixed method was adopted and through the qualitative and quantitative methods, the objectives were explored. The used research design is a sequential explanatory 
technique. The positive reinforcement techniques and the school social work interventions were identified by using a semi-structured interview guide for four samples and four key informants. The sampling method is purposive sampling and the collected data were analyzed by thematic analysis. The positive reinforcement's effectiveness was measured under simple random sampling from 30 schools out of 60 schools. The used tool is a questionnaire with four scales and the collected data were analyzed by SPSS.

The phase of this study was divided into three parts. They are,

In phase one, the researcher used the qualitative method (interview schedule) to identify the positive reinforcement techniques applied by school teachers on primary students from selected four samples.

In phase two, the researcher used a quantitative method (questionnaire) from 30 teachers to measure the effectiveness of the positive reinforcement techniques which were identified from the selected four samples through the interview schedule. Here, the Sequential explanatory design was used.

In phase three, the researcher used the qualitative method (interview schedule) to identify the school social work intervention methods to promote positive reinforcement techniques from the selected four key professionals who experts in the relevant field.

\section{FINDINGS}

The characteristics of the respondents include,

In qualitative inquiry, the researcher adopts purposive sampling. The respondent characteristics are discussed in bellow Table number 01,

Table Number 01

\begin{tabular}{|c|c|c|c|}
\hline $\begin{array}{c}\text { Sample } \\
\text { Number }\end{array}$ & Profession & Experience & Educational Qualification \\
\hline 01 & Teacher & 34 & $\begin{array}{c}\text { Bachelors Education in } \\
\text { Primary (B.Ed.) }\end{array}$ \\
\hline 02 & Teacher & 30 & $\begin{array}{c}\text { B.A Graduate, Dip in } \\
\text { Education, Primary Trained } \\
\text { Distance study special in } \\
\text { Primary training (4 years) }\end{array}$ \\
\hline 05 & Teacher & 26 & $\begin{array}{c}\text { Teaching Training college } \\
\text { Specialized in Primary } \\
\text { education }\end{array}$ \\
\hline 01 & $\begin{array}{c}\text { Tecturer in } \\
\text { Teachers' } \\
\text { Training College }\end{array}$ & 35 & $\begin{array}{c}\text { M.Phil. in Primary } \\
\text { Education, Bachelors in } \\
\text { Psychology }\end{array}$ \\
\hline 02 & $\begin{array}{c}\text { Lecturer in } \\
\text { Eastern University } \\
\text { of Sri Lanka }\end{array}$ & 35 & $\begin{array}{c}\text { B.Sc. (Agri), PGDE, } \\
\text { PGDEM, SLEAS, M.Sc. } \\
\text { (Education), M.Phil., Ph.D. } \\
\text { (Education) }\end{array}$ \\
\hline 03 & $\begin{array}{c}\text { Additional } \\
\text { Director of } \\
\text { Primary Unit }\end{array}$ & 34 & $\begin{array}{c}\text { B.A, PGD in Education, } \\
\text { Primary training, M.A in } \\
\text { Education }\end{array}$ \\
\hline \multirow{2}{*}{$\begin{array}{c}\text { Additional } \\
\text { Director of } \\
\text { Primary Unit }\end{array}$} & 31 & $\begin{array}{c}\text { A/L, } \\
\text { Distance study in Primary } \\
\text { Trained Teachers Training } \\
\text { College }\end{array}$ \\
\hline
\end{tabular}

In Quantitative inquiry, the researcher adopts simple random sampling. The characteristic of the respondent explains in Diagram number 02.

Diagram Number 02

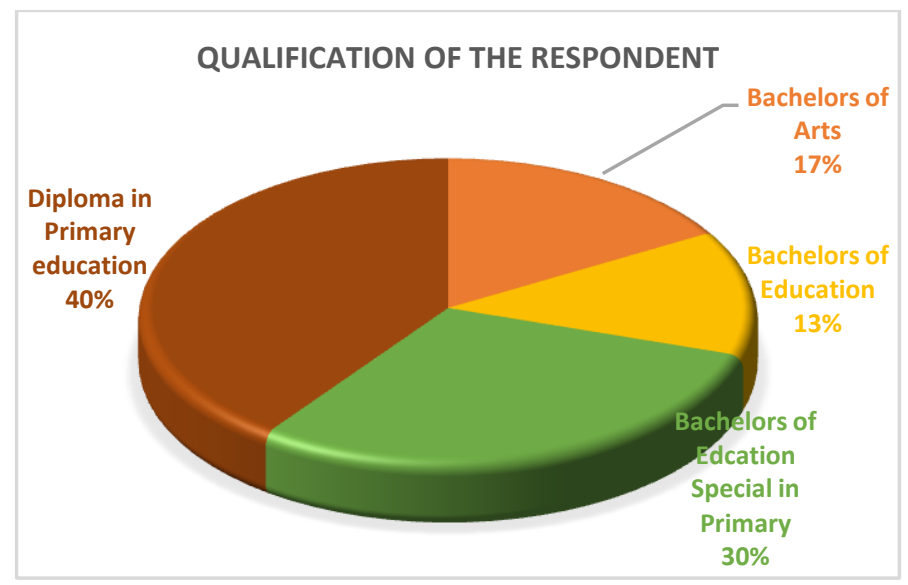

In the qualification of the respondents, the teachers from Diploma in primary education is $40 \%$, Bachelors of Arts is $17 \%$, Bachelors of Education is $13 \%$ and Bachelors of Education special in Primary is $30 \%$.

The positive reinforcement techniques were identified through the semi-structured interview and the effects were measured by questionnaire.

The techniques were categorized under sensory reinforcement, natural reinforcement, material reinforcement, generalized reinforcement, and social reinforcement. According to Alberto \& Troutman, they categorized the positive reinforcement techniques into 5 types based on behavior analysis. The researcher used this as the model and developed the concepts.

The researcher composite the data by using experience and profession. According to (Podolsky, 2016) Teaching experience is positively associated with student achievement gains throughout a teacher's career and as teachers gain experience, their students not only learn more, as measured by standardized tests, they are also more likely to do better on other measures of success, such as school attendance. Through getting experience a person can easily understand the particular situation. It helps in the teaching process. Therefore the researcher used experienced teachers to collect data.

All the respondents from the selected 30 school were strongly agreed in using positive reinforcement increase the desired behavior of the student and by using the different positive reinforcement techniques, they are helpful in teaching.

\subsection{Sensory Reinforcement}

The term 'sensory reinforcement' refers to the sensations that an individual might hear, see or feel in response to particular behaviors. If the consequences are pleasant the individual is more likely to show these behaviors again in the future so that they can have the experience again. The sensation happens through smell, touch, see and hear. 
From the respondents the techniques they are using are,

Allow the student to touch and play with clay. According to Patty Storms in Importance of Clay and Pottery in Child Development says, "clay is a unique art medium because it is highly responsive to touch and very forgiving. As soon as children are given clay, they immediately begin to meld and shape it. They become aware that they are in charge and have influence over the medium as it is quick to respond to their fingers. The feeling that they are in command of the clay gives the students the confidence to attempt any project which opens the door to greater self-expression and imagination'. (Storms). Through playing with clay the student can enhance their capacity in gaining Self- confidence and innovative thinking. Touching the clay straight deals with the human body. Therefore the researcher categorizes this technique under sensory reinforcement. The effectiveness of the particular technique is in Diagram no 3.

Diagram number 03

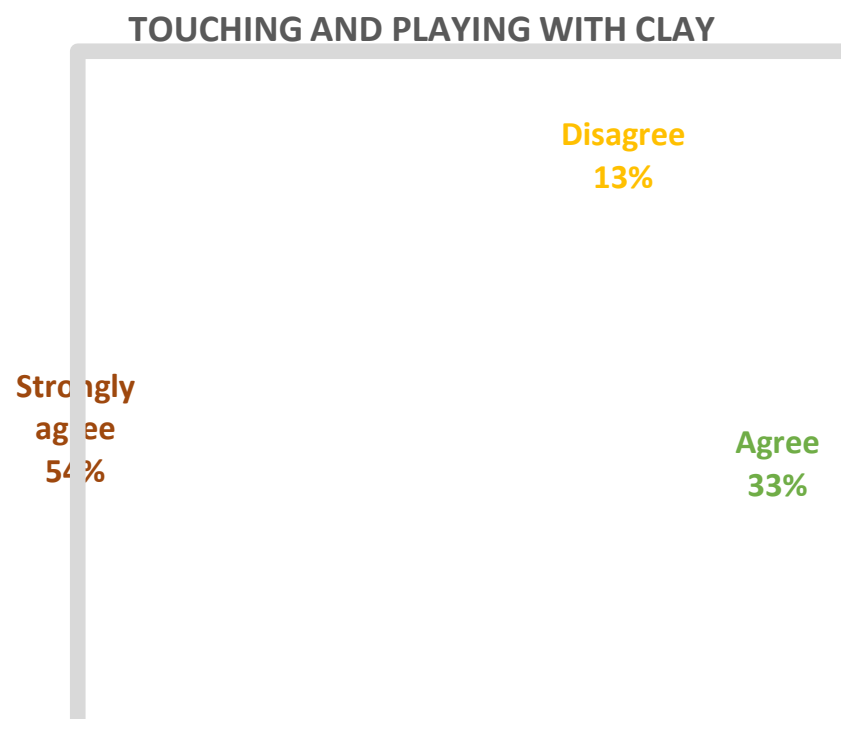

Source: Field Data 2018

In the response of touching and playing with clay increase the desirable behavior high in academic performances, $13 \%$ of people disagreed while $54 \%$ of people have strongly agreed and $33 \%$ of people agreed. From the overall perspective, most of the teachers accept this statement.

The next technique is allowing the student to touch and play with the building blocks. According to (Committee, 2007), the kids who showed more interest in construction and built more sophisticated structures are performed better on a standardized test of spatial intelligence. Therefore the need of the play which represents construction is important in childhood. This construction plays known as building blocks and when students build this they can able to get motivated and perform well. The effectiveness of the particular technique is in Diagram no 4
Diagram number 04

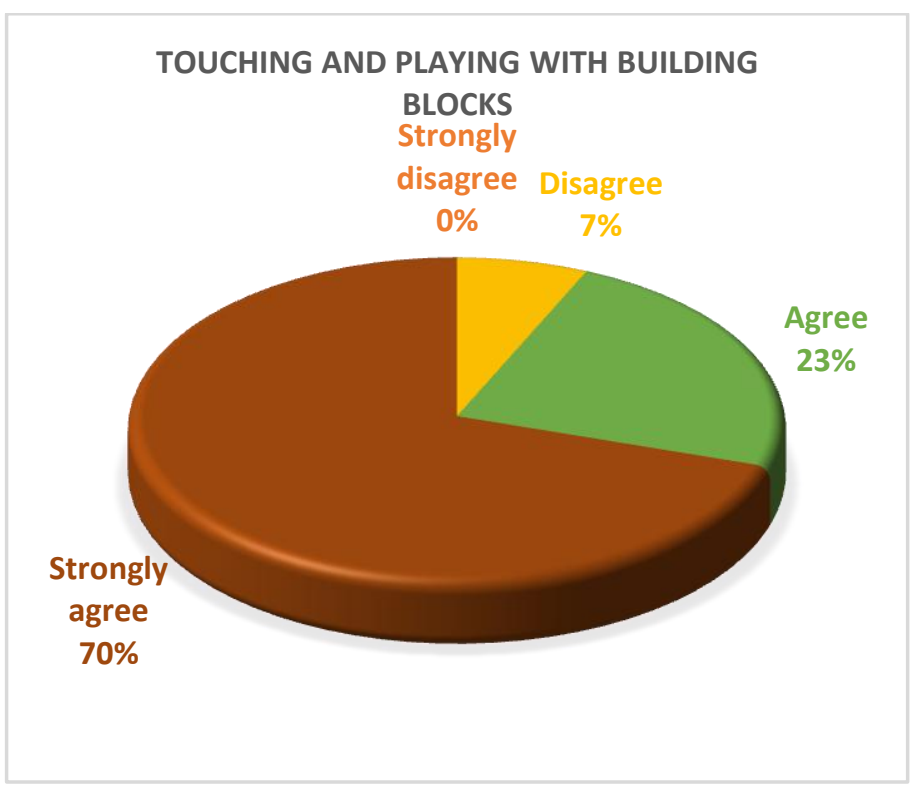

Source: Field Data 2018

$70 \%$ of teachers strongly agreed and $23 \%$ of teachers agreed in touching and playing with building blocks increase the desirable behavior high in academic performances while $7 \%$ of teachers disagree with this opinion. In the overall perspective, most of the teachers accept this statement.

The next technique is to allow the students to hear the recorded stories. They hear the stories by using multimedia devices. The respondent said, when I played the recorded stories for the well-performed student, the others also felt curious to hear that. At this time I make a condition and use this as reinforcement' through this statement the teacher uses this technique to motivate the students. The effectiveness of the particular technique is in Diagram no 5.

Diagram number 05

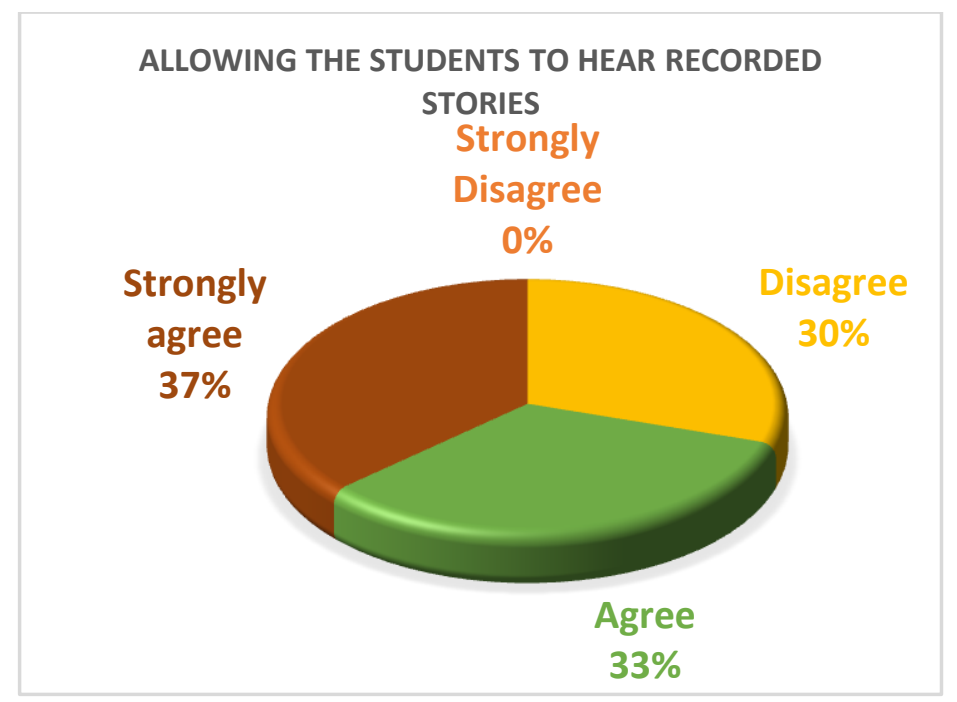

Source: Field Data 2018 
$37 \%$ of teachers strongly agreed and $33 \%$ of teachers agreed that allowing the students to hear recorded stories increase the desirable behavior high in academic performances while $30 \%$ of teachers have disagreed. In the overall perspective, most of the teachers accept this statement.

The next technique the researcher identified is showing cartoons and videos for the students. Cartoons have been related to children since they started to appear on newspapers and television and many adult people also watch cartoons. With good guidance and proper limitations, cartoons have benefits such as awareness of social life, build their vocabulary, the boost of concentration, and a good form of entertainment. (Nelsen, n.d.). The effectiveness of the particular technique is in Diagram no 6.

Diagram number 06

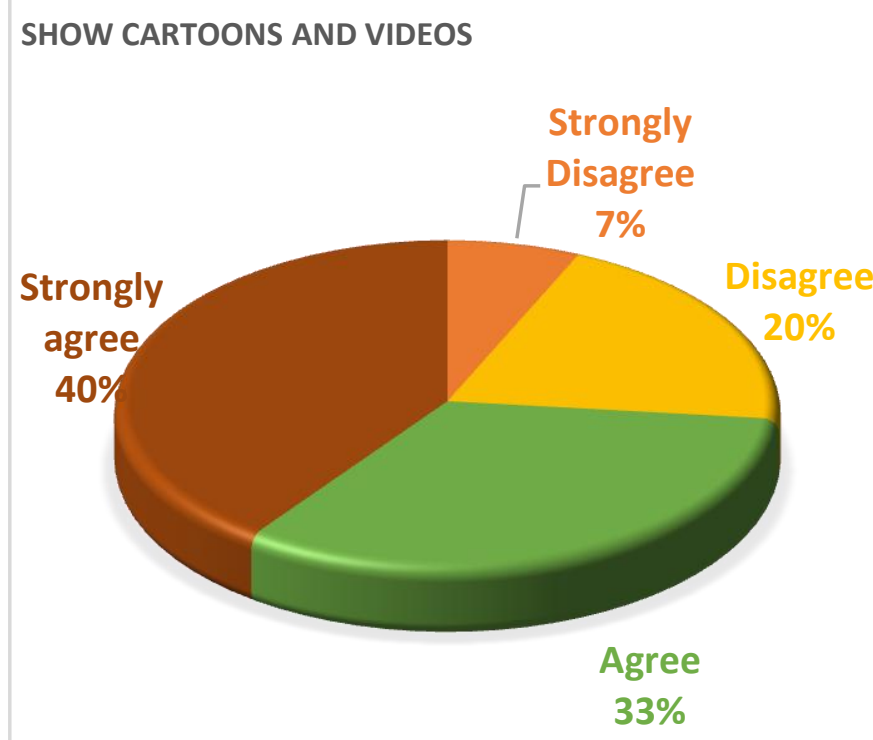

Source: Field Data 2018

$40 \%$ of teachers strongly agreed and $33 \%$ of teachers agreed that showing cartoons and videos increase the desirable behavior high in academic performances while $7 \%$ of teachers strongly disagreed and $20 \%$ of teachers disagreed. In the overall perspective, most of the teachers accept this statement.

The next technique the researcher has identified under sensory reinforcement is, make the student blow bubbles. When blowing bubbles they use the wind through the mouth. Normally children like to blow bubbles and blast the bubbles. According to Practical Guild to Child Development (2015), Blowing bubbles helps the student to increase visual tracking skills, gross motor moments, balance and muscle tone development, fine motor development, hand-eye, and foot-eye coordination, oral-motor skills development, speech, hearing, and language development and body awareness. The effectiveness of the particular technique is in Diagram no 7.
Diagram number 07

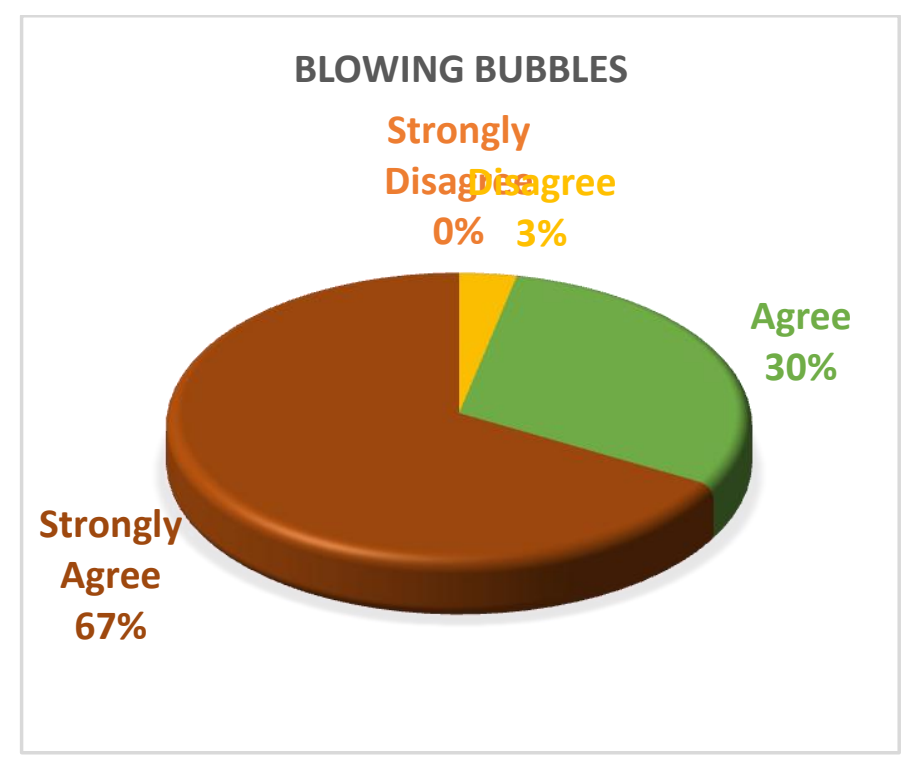

Source: Field Data 2018

$67 \%$ of teachers strongly agreed and $30 \%$ of teachers agreed in allowing the students to blow bubbles increases the desirable behavior high in academic performances while 3\% of teachers disagreed. In the overall perspective, most of the teachers accept the statement.

The researcher has identified 5 techniques in sensory reinforcement. One of the respondents states, "when the student once feels the touching with the particular techniques they continuously ask me to use the same technique again' from this statement the sensory reinforcement motives the student to repeat the behavior. These techniques were directly deal with the body parts. The sensor formation can be felt while applying these techniques. Therefore, the researcher categorizes these techniques under sensory reinforcement, and in each of the techniques, the respondents gave their measurements. Through this, the effectiveness of sensory reinforcement was measured.

In the holistic view of sensory reinforcement, most of the teachers accept that sensory reinforcement's techniques increase the desired behaviors in academic performances.

\subsection{Natural Reinforcement}

According to (Horcones, 1992) natural reinforcement defines "Intrinsic consequences are the changes in stimulation produced by the behavior itself. Thus, a behavior is naturally reinforced when the intrinsic consequences it produces function as reinforces". The naturally occurring phenomenon can be categorized under natural reinforcement.

From the respondents the techniques they used under natural reinforcement are,

Allow the student to play in the classroom or ground. The teacher makes a condition by using this as a reinforcing mechanism. Kenneth R. Ginsburg and the Committee on 
Communications, and the Committee on Psychosocial Aspects of Child and Family Health (2007) addressed, Play allows children to use their creativity while developing their imagination, dexterity, and physical, cognitive, and emotional strength. Play is important to healthy brain development. Play allows children to create and explore a world they can master, conquering their fears while practicing adult roles, sometimes in conjunction with other children or adult caregivers.

Playing is an interesting activity for primary students. Most students like to play at their small ages. When the teacher allows the student to play under one condition, the condition is more like to be achieved by the student. This motivates to increase the desirable behavior high.

The respondent said, 'all the students in my classroom are like to play. They often ask me to allow them to play after finishing the works. But I said this is the classroom. Score well in the next spelling test. After that, I will allow you ' through this statement teacher is making one condition with one reinforce. This reinforcement comes under natural reinforcement. The effectiveness of the particular technique is in Diagram no 8.

Diagram number 08

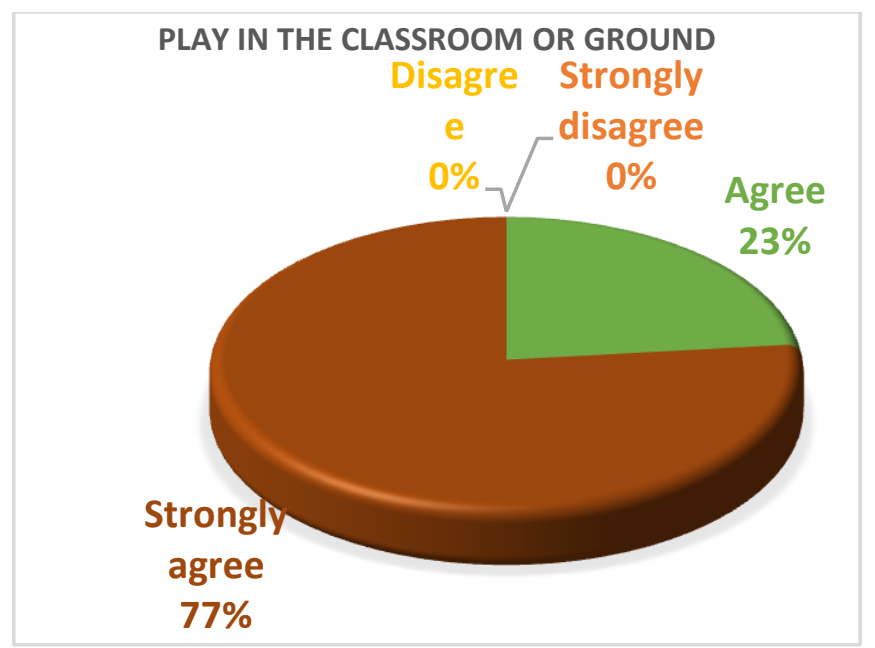

Source: Field Data 2018

$77 \%$ of teachers strongly agreed and $23 \%$ of teachers agreed to allow the students to play in the classroom or ground increase their desirable behavior high in the academic performances while no one strongly disagreed or disagreed. In the overall perspective, all teachers accept this statement

The next technique the researcher identified is, make the student erase the blackboard. In the research area, teachers are using the blackboard to teach the lessons. When the lesson is finished the blackboard will be erased by the monitor in the classroom. Some students like to erase the board. Therefore the teachers use the student's likeness as one technique.

One of the respondents said, "when I finished teaching on the blackboard, the students ask me 'teacher...can I erase the board?'. These kinds of situations occur in the classroom naturally. The effectiveness of the particular technique is in Diagram no 9.

Diagram number 09

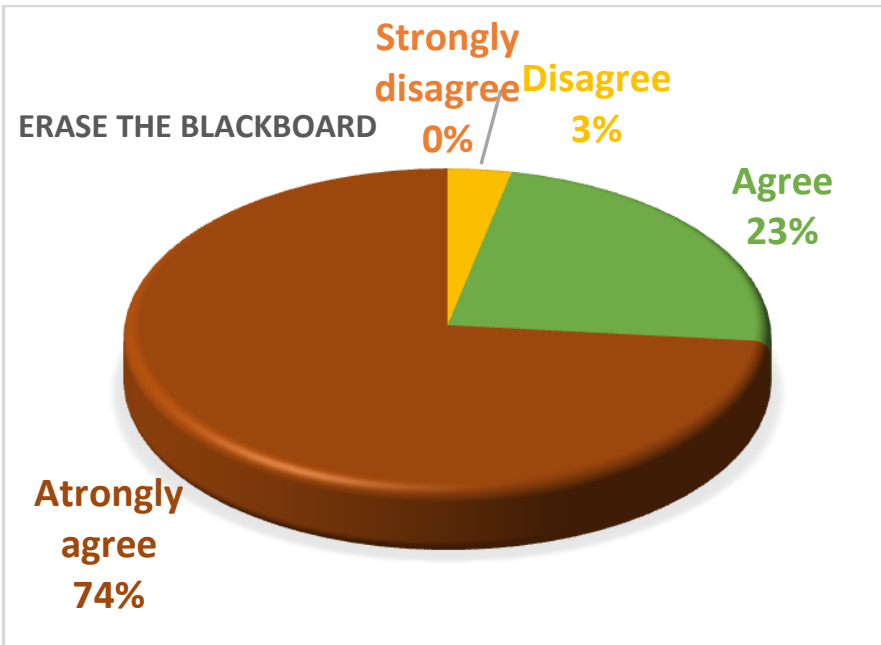

Source: Field Data 2018

$74 \%$ of teachers strongly agreed and $23 \%$ of teachers agreed in allowing the students to erase the blackboard increase the desirable behavior high in the academic performances while $3 \%$ of people disagreed. In the overall perspective, most of the teachers accept this statement.

The next technique is being the person who does minor works which the teacher says. Doing works such as taking attendance books and putting record books are very much preferable for some students. The respondent said, when I give the work to one performing student, other students also try to perform. Because they think if they perform well then I will tell them to work'. This situation happens in the classroom setting. It can perceive as a natural phenomenon. The effectiveness of the particular technique is in Diagram no 10.

Diagram number 10

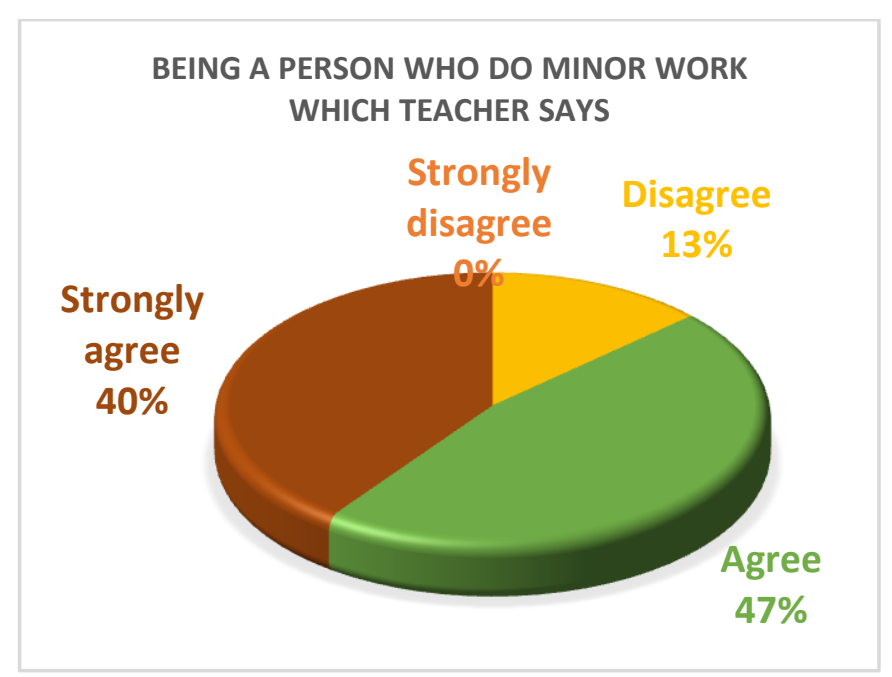

Source: Field Data 2018 
$40 \%$ of teachers strongly agreed and $47 \%$ of people agreed in allowing the student to do minor works which the teacher says will increase the desirable behavior high in academic performances while $13 \%$ disagreed. In the overall perspective, most of the teachers accept this statement

The next technique in natural reinforcement is to make the student sit near to the favorite friend. Students have friends in their class. Sometimes the teacher divides the friends and separates them. When the teacher uses this as reinforcement and gives one condition, the students wish to fill that condition. The respondent said, 'I don't allow the student to sit with their friends, because they shout and disturb the class. But I make them sit together when they performed well in the activities'. The effectiveness of the particular technique is in Diagram no 11.

Diagram number 11

\section{SITTING NEAR TO THE FRIEND}

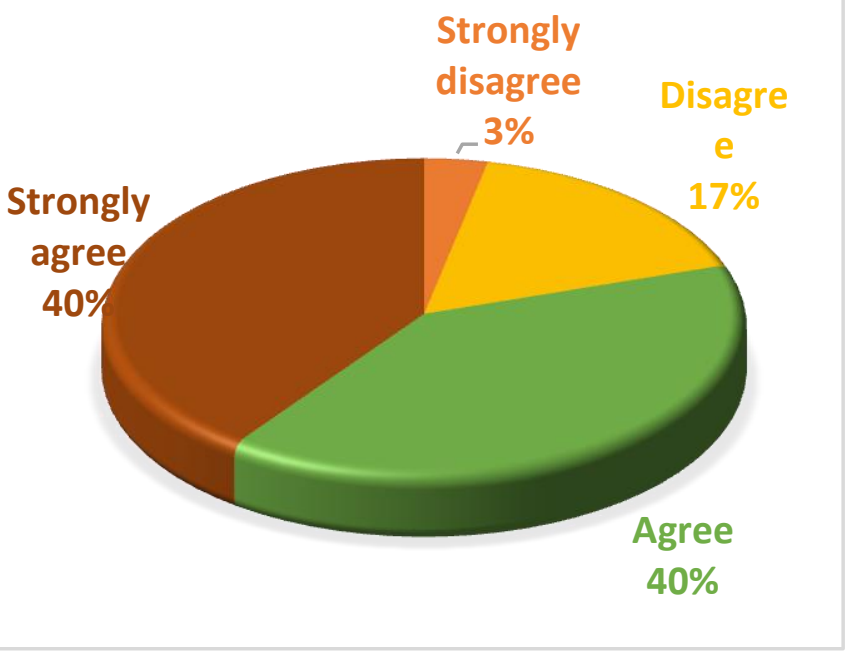

Source: Field Data 2018

$40 \%$ of teachers strongly agreed and $40 \%$ of teachers agreed in allowing the students to sit near the favorite friend will increase the desirable behavior high in the academic performances while $17 \%$ of teachers disagreed and $3 \%$ of teachers strongly disagreed. In the overall perspective, most of the teachers accept this statement.

The next technique the researcher has identified is, make the student read a story book. According to the Cam Everlands Primary School's research report says, using reading storybooks as a technique will increase the student's concentration power, increase brain power, and improving vocal and language skills. The effectiveness of the particular technique is in Diagram no 12.
Diagram number 12

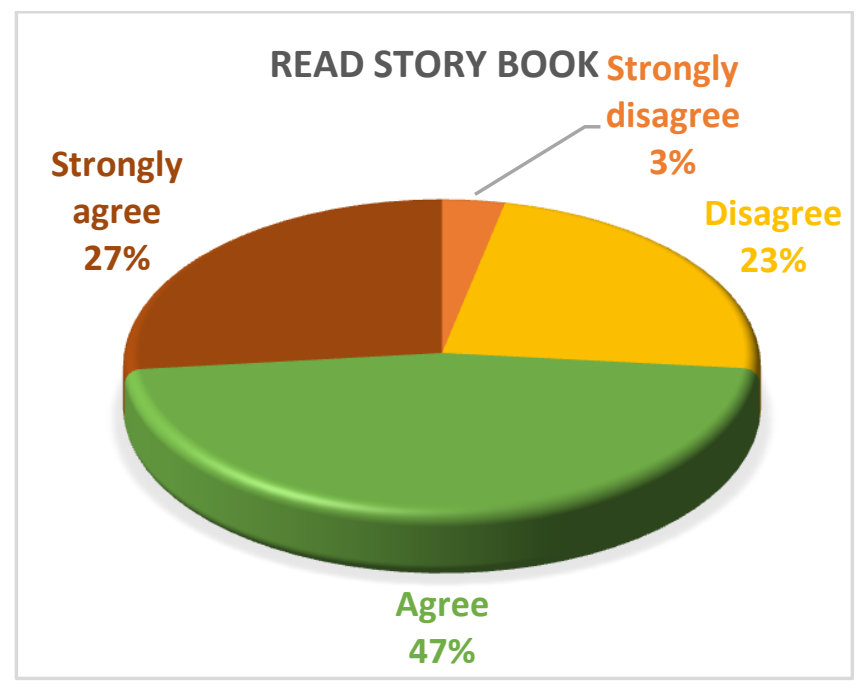

Source: Field Data 2018

$27 \%$ of teachers strongly agreed and $47 \%$ of teachers agreed in reading story book make the student increase the desirable behavior high in academic activities while $23 \%$ of teachers disagreed and $3 \%$ of people strongly disagreed. In the overall perspective, most of the teachers accept the statement.

Under natural reinforcement, 5 techniques were identified and measured. In the holistic view, most of the teachers accept that techniques under natural reinforcement increase the desirable behavior high in the academic performance.

\subsection{Material Reinforcement}

According to the study conducted in Hunter College, New York, it explains the token economy serves as a tool for enhancing levels of self-efficacy and providing opportunities for students to view their behaviors as self-determined. In this way, the token economy can be viewed as a mechanism for enhancing levels of intrinsic motivation through the use of external rewards. Materials are the thing which can touchable and feel. The material refers to the token. These rewards are given by the respondents to the students in the classroom. (Ofordile) Asserted that material reinforcement increases behavior, for reinforcement to be optimally useful, it must be delivered soon after the desired behavior has occurred.

According to the Ministry of Education in Guyana, an effective behavior modification system within the classroom often includes rewards. Students are motivated to achieve and conform to appropriate behaviors when either intrinsically or extrinsically rewarded. Those students who prefer intrinsic motivation enjoy praise, personally challenging projects, and accomplishing educational tasks just for the love of learning. An extrinsic approach requires more tangible rewards such as pencils, erasers, stickers, and sometimes candy. The type of reward given to students must be fair and consistent for all students but also must vary for each task. 
From the respondents the techniques used under material reinforcement are,

Giving stickers to the students. The respondent said, "when I give stickers for the students they enjoying by sticking in the books and showing to others'. The effectiveness of the particular technique is in Diagram no 13.

Diagram number 13

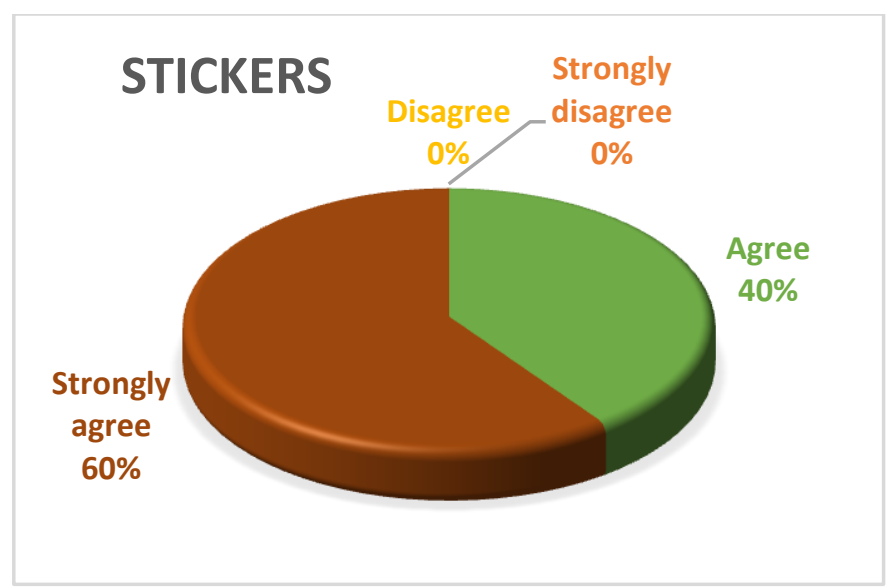

Source: Field Data 2018

$60 \%$ of the teacher strongly agreed and $40 \%$ of teachers agreed in giving stickers increase the desirable behavior high in the academic performances while no one strongly disagreed and disagreed. In the overall perspective, all the respondents accept this statement.

The next technique the researcher has identified is giving clay to the students. By giving clay the student can touch and play with that. The effectiveness of the particular technique is in Diagram no 14.

Diagram number 14

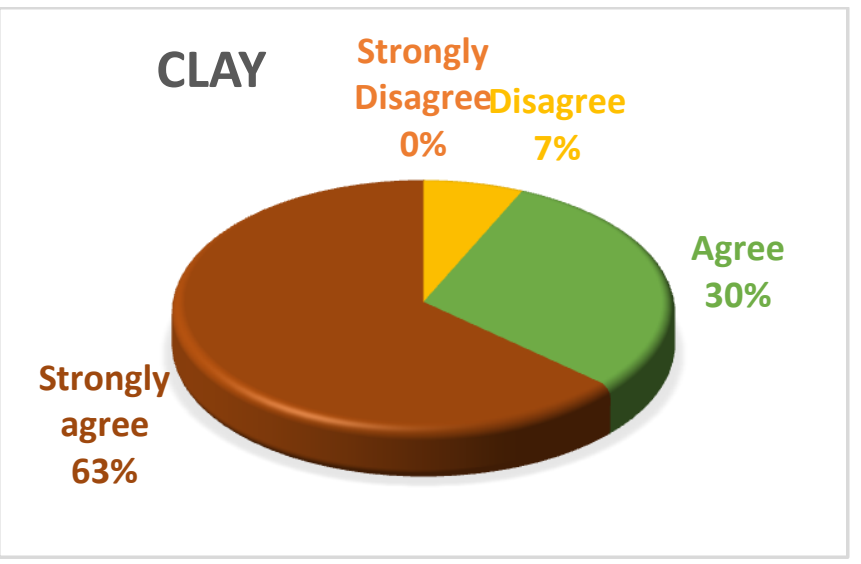

Source: Field Data 2018

$63 \%$ of teachers strongly agreed and $30 \%$ of teachers agreed in giving clay to the students to increase their desirable behavior high in academic performances while $7 \%$ of teachers disagreed. In the overall perspective, most of the teachers agreed with this statement
The next technique is giving pencils to the students. The students use the pencils to write in the copies. The common thing that the teacher gives to the student is the pencil. The effectiveness of the particular technique is in Diagram no 15.

Diagram number 15

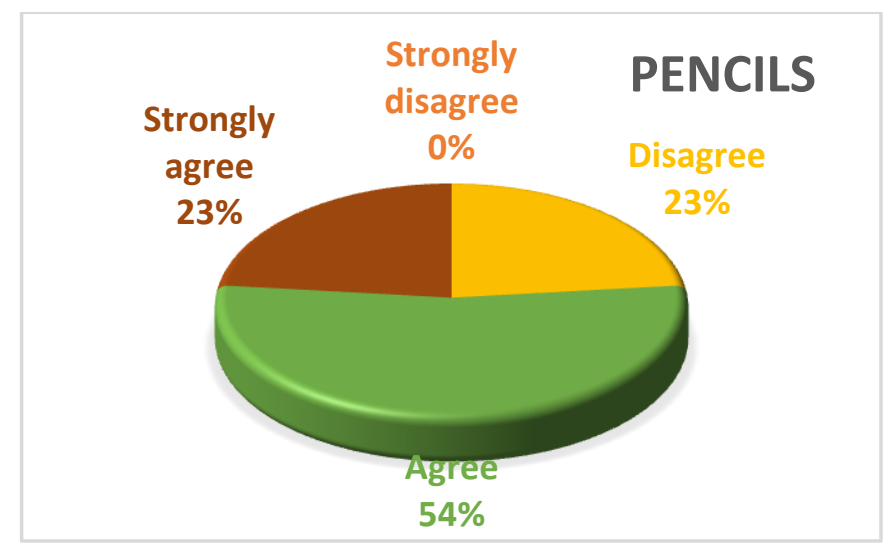

Source: Field Data 2018

$23 \%$ of teachers strongly agreed and $54 \%$ of teachers agreed in giving pencils for the students will increase their desirable behavior high in academic performances. In the overall perspective, most of the teachers accept this statement.

The next technique the researcher identifies is giving copies to the students. By giving copies to the students the teachers can see changes in their performances.

One respondent said, I give a copy for the student who performed well and says to all students that if you want copies you should gain more marks on the next test'.The effectiveness of the particular technique is in Diagram no 16.

Diagram number 16

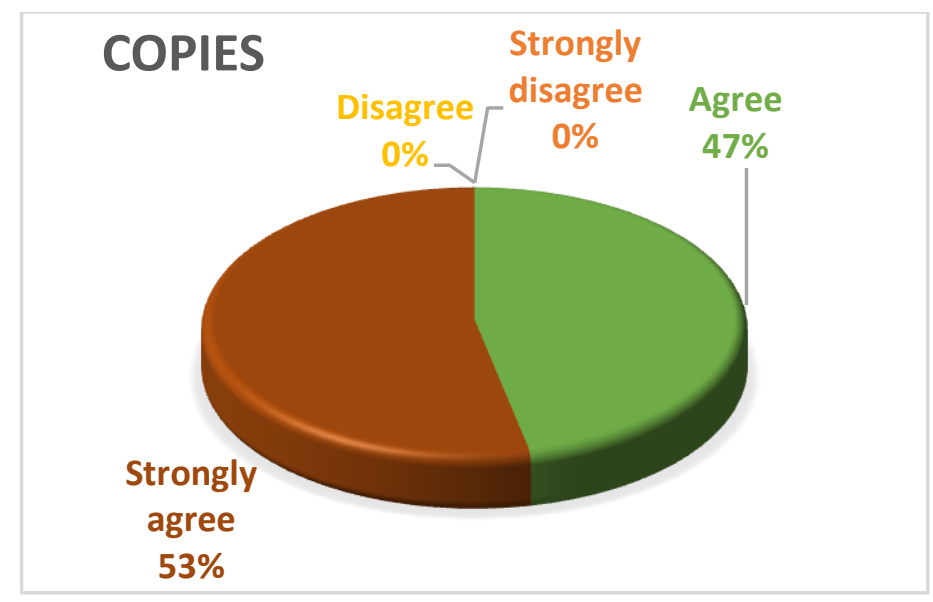

Source: Field Data 2018

$53 \%$ of teachers strongly agreed and $47 \%$ of people agreed that giving copies increase the desirable behavior high in academic performances while no one strongly disagreed and disagreed. In the overall perspective, all of the teachers agreed on this statement. 
The next technique the researcher has identified is giving erasers. Erasers use to erase the pencil marks. The respondent said, 'Erasers are in different colors and shapes. It looks attractive. All the students in my classes are like to get erasers'. The effectiveness of the particular technique is in Diagram no 17.

Diagram number 17

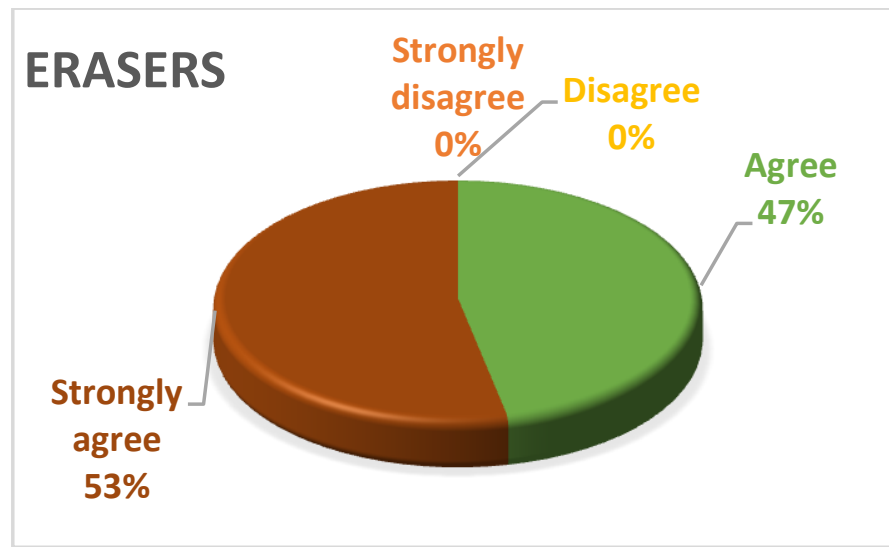

Source: Field Data 2018

$53 \%$ of teachers strongly agreed and $47 \%$ of teachers agreed in giving erasers increases the desirable behavior high while no one strongly disagreed and disagreed. In the overall perspective, all the teachers agreed on this statement.

The next technique is giving toffees for the student. There are varieties of toffees in the shops. When the student gets the toffees, they feel happy inside. The respondent said, 'I don't use costly toffees to give students and they also didn't expect costly toffees from me. When I give toffees with my hand they feel happy and smile at me'. The effectiveness of the particular technique is in Diagram no 18.

Diagram number 18

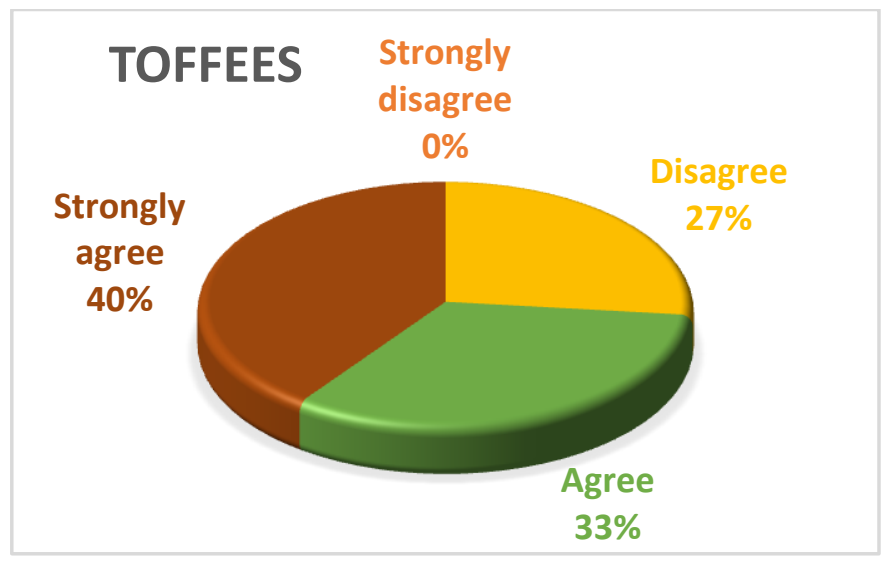

Source: Field Data 2018

$40 \%$ of teachers strongly agreed and $33 \%$ of teachers agreed in giving toffees increases the desirable behavior high in academic performances while $27 \%$ of teachers disagreed. An overall perspective most of the teachers accept on this statement.

The next technique the respondent use is giving sharpeners for the students. The effectiveness of the particular technique is in Diagram no 19.

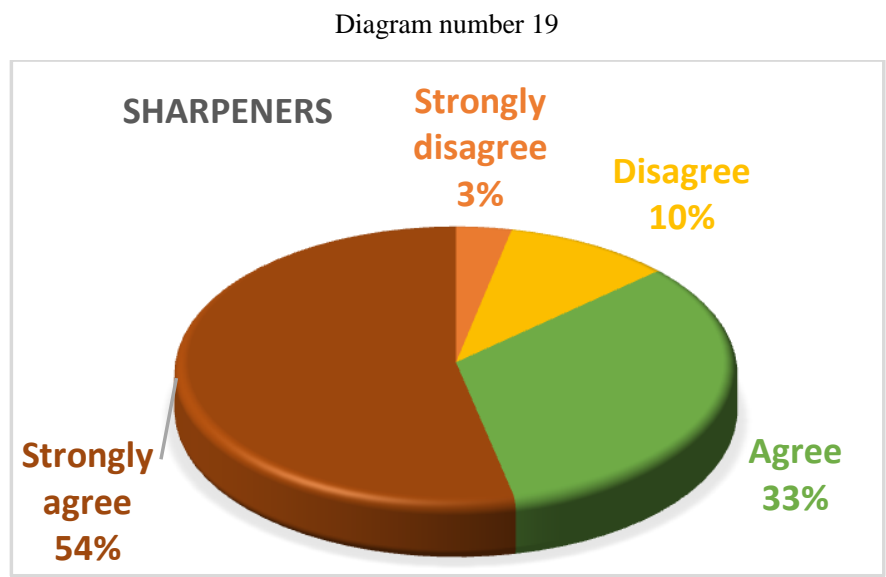

Source: Field Data 2018

$54 \%$ of teachers strongly agreed and $33 \%$ of people agreed in giving sharpeners increase the desirable high in academic performances while $3 \%$ of teachers strongly disagreed and $10 \%$ of teachers disagreed. In the overall perspective, most of the teachers agreed with this statement.

Under material reinforcement, the above techniques were identified and the effects were measured. One of the respondents said, 'I don't use all the material to reward the student. I use some specific things to give the students. Because the materials should be equally provided and it will be money consuming' through this statement, that this respondent is using some limited number of materials to give the student. The materials provided are money-consuming and limited. The teachers are using the materials with the concern of their availability and credibility.

In the holistic view of material reinforcement, most of the respondents agreed that using techniques under material reinforcement increase the desirable behavior high in academic performances.

\subsection{Generalized Reinforcement}

A generalized reinforcement is a conditioned reinforcement that has obtained the reinforcing function by pairing with many other reinforces and functions as reinforce under a wide variety of motivating operations. Skinner (1953), suggests that generalized reinforcement is more effective because it is less dependent on the momentary deprivation of the organism and the same response may precede a variety of reinforcements on different occasions and under different deprivations, thus increasing the probability of the future occurrence of the response. 
A generalized reinforcement is any item that can later be exchanged for something of value. This is an excellent method to help students.

The techniques identified under generalized reinforcement are,

Giving tokens to the students. According to the English Oxford Dictionary 'A thing serving as a visible or tangible representation of a fact, quality, feeling, etc.' One of the respondents said, 'I can't get back tokens which I gave to the student, and if I do like that the student can get upset easily. The effectiveness of the particular technique is in Diagram no 20.

Diagram number 20

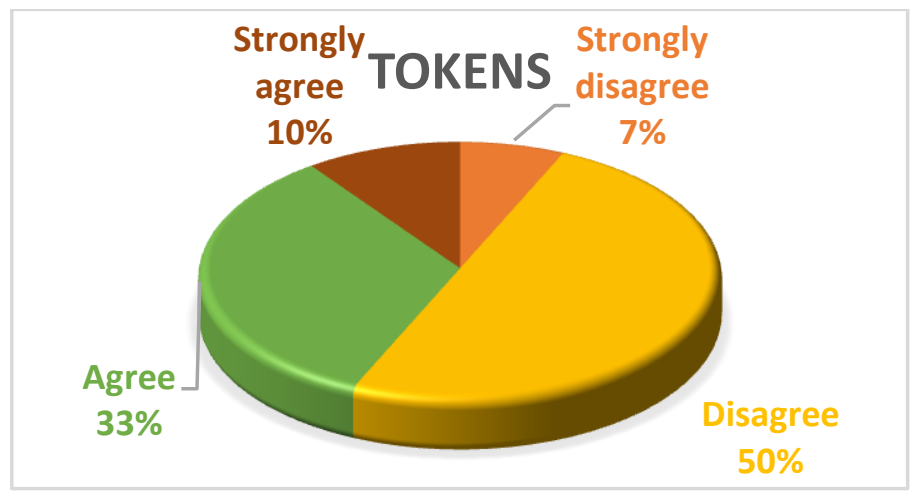

Source: Field Data 2018

$10 \%$ of teachers strongly agreed and $33 \%$ of teachers agreed in giving tokens increases the desirable behavior high in academic performance while $50 \%$ of teachers disagreed and $7 \%$ of teachers disagreed. In the overall perspective, most of the teachers don't agree that on this statement.

The next technique is giving credits to the students. To exchange the values for reward teachers use credits to the student. One of the respondents said, 'some teachers give the credits for the students. But it will lead to motivate the student negatively'. The effectiveness of the particular technique is in Diagram no 21.

Diagram number 21

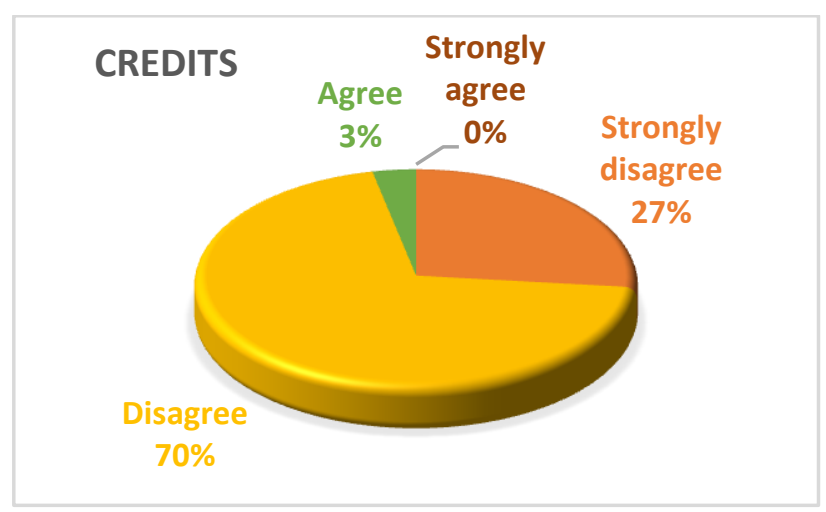

Source: Field Data 2018
$3 \%$ of teachers agreed that giving credits increases the desirable behavior high in the academic performances while $27 \%$ of teachers disagreed and $70 \%$ of teachers disagreed. In the overall statement, a huge number of teachers don't agree with this statement.

The next technique the teachers use is giving points to students. These points are given by marks. According to (Tynan, 2017) said that giving points will increase motivation and boost self-esteem. The effectiveness of the particular technique is in Diagram no 20.

Diagram number 22

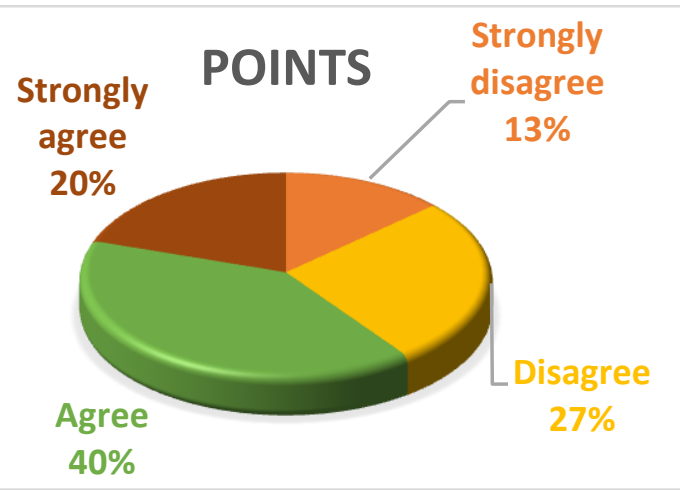

Source: Field Data 2018

$20 \%$ of teachers strongly agreed and $40 \%$ of teachers agreed in giving points to increase the desirable behavior high in academic performances while $27 \%$ of teachers disagreed and $13 \%$ of teachers strongly disagreed. An overall perspective most of the teachers accept this statement.

The next technique the researcher has identified is marking $\mathrm{v}$. good by red pen in student's copies. Teachers use a red pen to mark right or wrong in the copies. A study in the 2008 European Journal of Social Psychology suggested that red pens may potentially make teachers more likely to spot errors on tests and be more critical. When the teacher doesn't spot mistakes and marks v.good the student automatically gets stimuli to perform well. The effectiveness of the particular technique is in Diagram no 23.

Diagram number 23

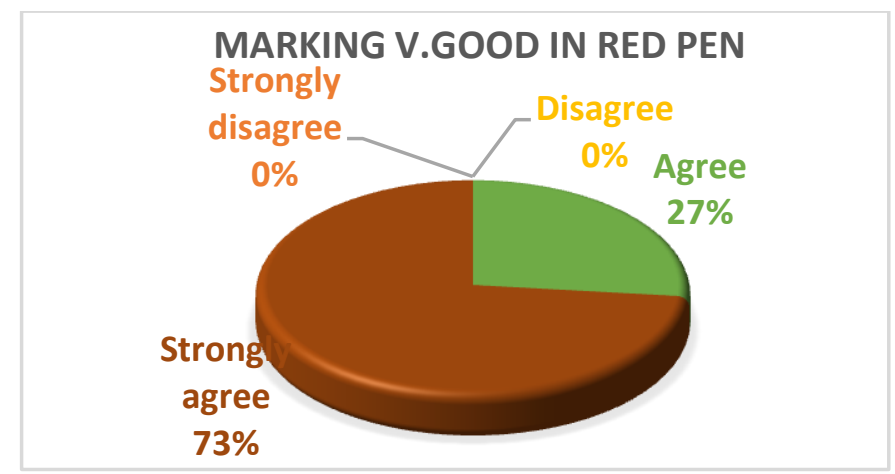

Source: Field Data 2018 
$73 \%$ of teachers strongly agreed and $27 \%$ of teachers agreed in marking v.good in red pen on student's copies increase the desirable high in the academic performances while no one disagreed and strongly disagreed. In overall perspective, all teachers accept this statement.

Under generalized reinforcement, 4 techniques were identified. In the technique of giving credits and giving tokens, most of the teachers don't agree that those techniques increase the desirable behavior high in the academic performances. But in the other two techniques, most of the teachers agreed that those techniques increase the desirable behavior high in the academic performances.

\subsection{Social Reinforcement}

Social reinforces are very effective when used alone. However, they are often paired or used simultaneously when giving other reinforces. Social rein forcers can be in verbal reinforcement which includes praise, a smile, and time free of going on a field trip (Cotton, 2006). Social rein forcers also include "thumbs up, a compliment, a pat on the balk, encouragement, recognition and an approving smiles" (Students' First, 2012). Social reinforcement can be verbal and non-verbal.

Under social reinforcement, the researcher has identified some techniques. They are,

A simple smile towards the student. According to (Copple, 1997) said, a teacher's smile is important on so many levels in the quest to reach students. She discussed that a teacher's smile can make the student feel free and motivate to ask the question, feeling safe so learning can take place and change the teacher's mood and student's mood.

One of the respondents said, 'merely a smile can't me stimulate the student, I use one of the material and give that with a smile'. The effectiveness of the particular technique is in Diagram no 24.

Diagram number 24

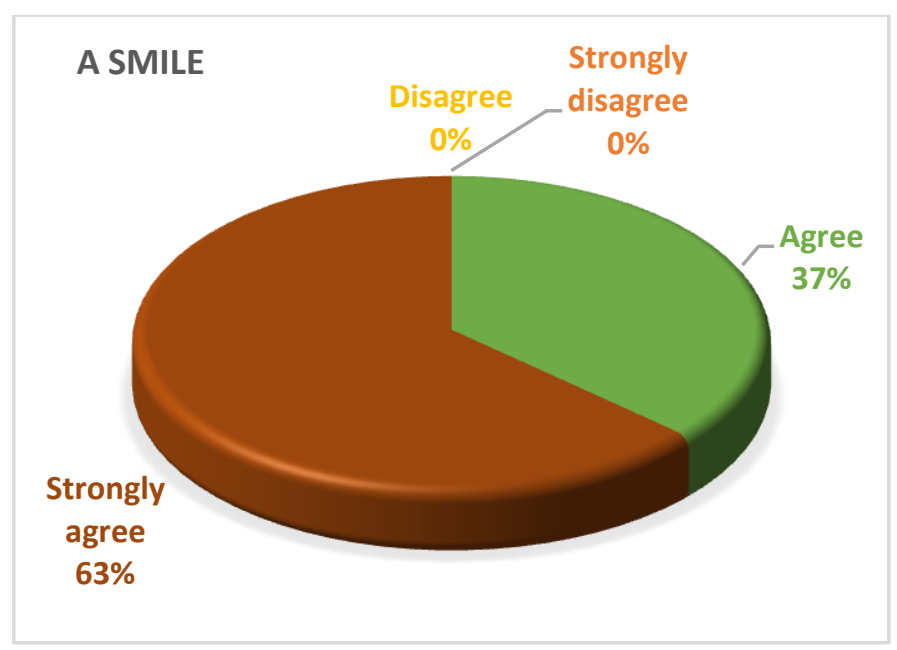

Source: Field Data 2018
$63 \%$ of teachers strongly agreed and $37 \%$ of teachers agreed in a smile towards students to increase the desired behavior in academic performances while no one disagreed or strongly disagreed. In the overall perspective, all teachers accept this statement.

The next technique under social reinforcement is the look of the teacher. The effectiveness of the particular technique is in Diagram no 25.

Diagram number 25

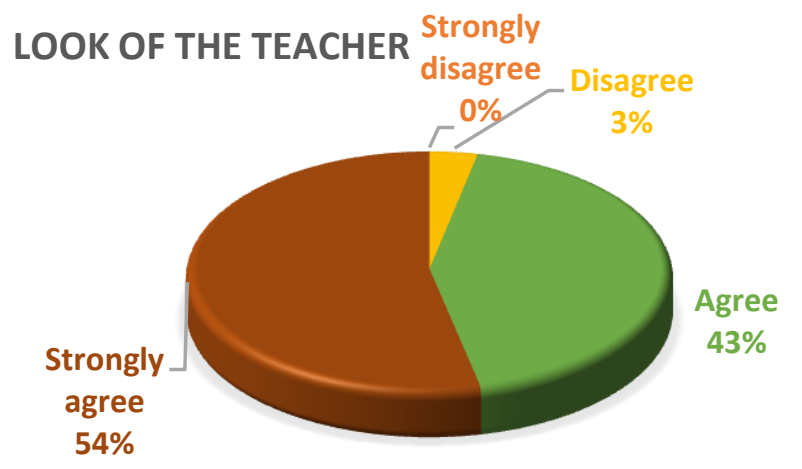

Source: Field Data 2018

$54 \%$ of teachers strongly agreed and $43 \%$ of teachers agreed in a look of the teacher increase the desirable behavior high in academic performances while $3 \%$ of teachers disagreed. In the overall perspective, most of the teachers accept this statement

The next technique the researcher has identified is, naming the student. One of the respondents said, 'I call the performed student and give the token to him. When I do like that the other students also get motive to get the reward.' Here in this statement, teachers use social reinforcement with the combination of generalized reinforcement. The effectiveness of the particular technique is in Diagram no 26.

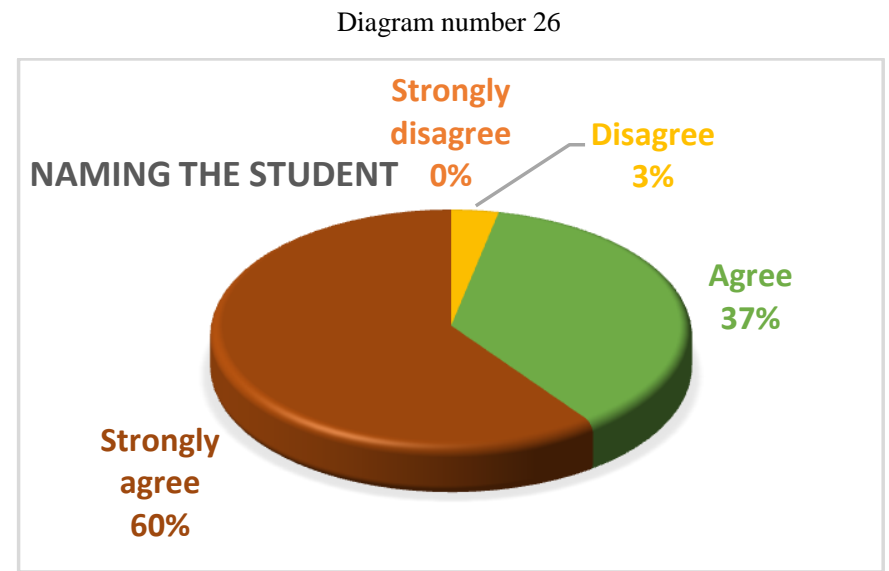

Source: Field Data 2018

$60 \%$ of the teachers strongly agreed and $37 \%$ of teachers agreed in naming the particular student increase the desirable high in the academic performances while $3 \%$ of teachers 
disagreed. In the overall perspective, most of the teachers accept this statement.

The next technique the researcher has identified is saying goods in front of the parents. One of the respondents said, "when I appreciate the student in front of his parents, later I can see the huge level of improvement in his academic activities' this statement shows the improvement of the students in the classroom. The effectiveness of the particular technique is in Diagram no 27.

Diagram number 27

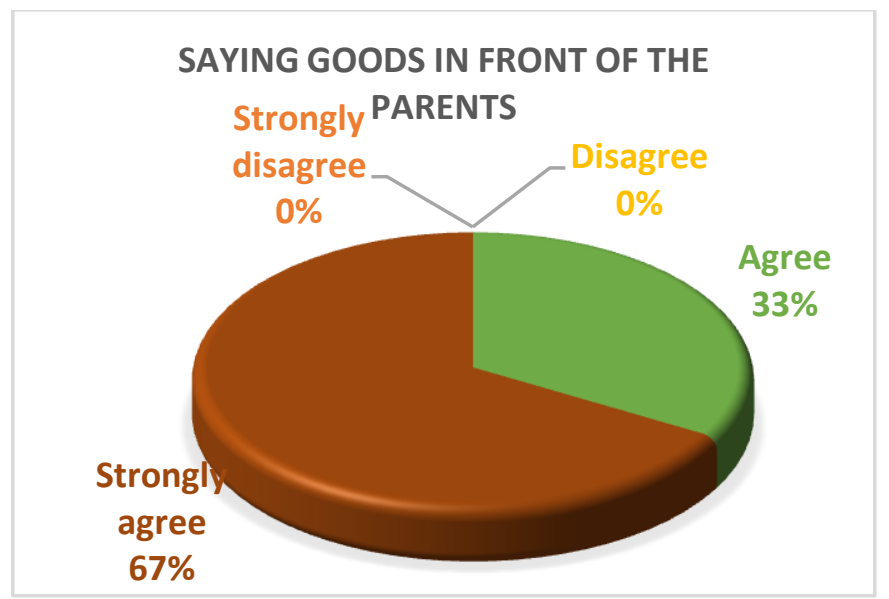

Source: Field Data 2018

$67 \%$ of teachers strongly agreed and $33 \%$ of teachers agreed in saying goods in front of the parents increase the desirable behavior high in the academic performances while no one disagreed and strongly disagreed. In the overall perspective, all of the teachers accept this statement.

The next technique the researcher has identified is pinching the cheeks of the students. One of the respondents said, 'Sometimes I slowly pinch the performed student's cheeks, after that, I can see that the performing level is maintaining without downing'. From this statement, the teacher uses this technique to maintain the performing level. The effectiveness of the particular technique is in Diagram no 28.

Diagram number 28

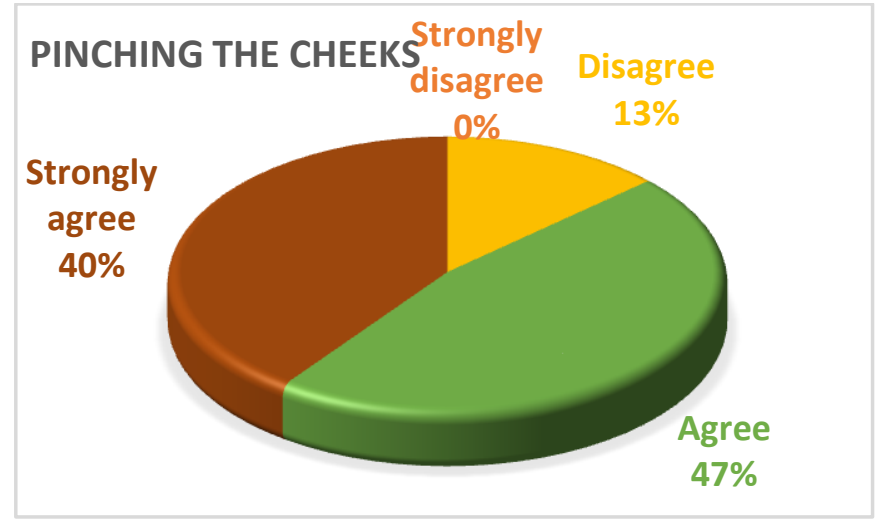

Source: Field Data 2018
$40 \%$ of teachers strongly agreed and $47 \%$ of teachers agreed in pinching the cheeks of the students increases the desirable behavior high in the academic performances while $13 \%$ of teachers disagreed. In the overall perspective, most of the teachers agreed with this statement

The next technique under social reinforcement is a small wink towards the student by the teacher. Some social reinforcement can't function alone. Because one of the respondents said that, 'I wink to the student when he gets more than 75 marks in the test. But I don't use it often. I use it once in a long time'. The effectiveness of the particular technique is in Diagram no 29.

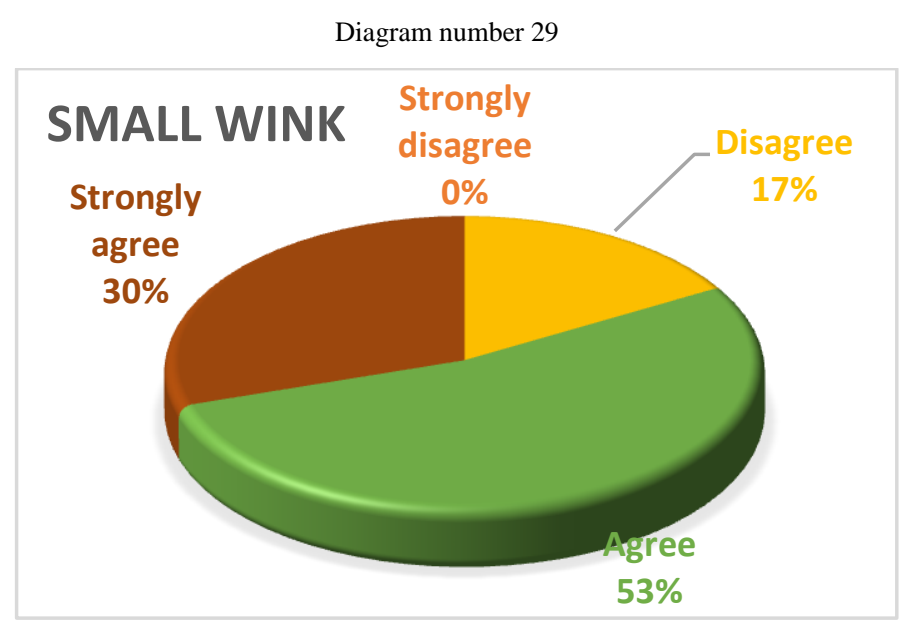

Source: Field Data 2018

$30 \%$ of teachers strongly agreed and 53\% of teachers agreed in small wink towards students increase the desirable behavior high in the academic performance while $17 \%$ of teachers disagreed. In the overall perspective, all of the teachers accept this statement.

The next technique the researcher has identified is standing near the student. The effectiveness of the particular technique is in Diagram no 30.

Diagram number 30

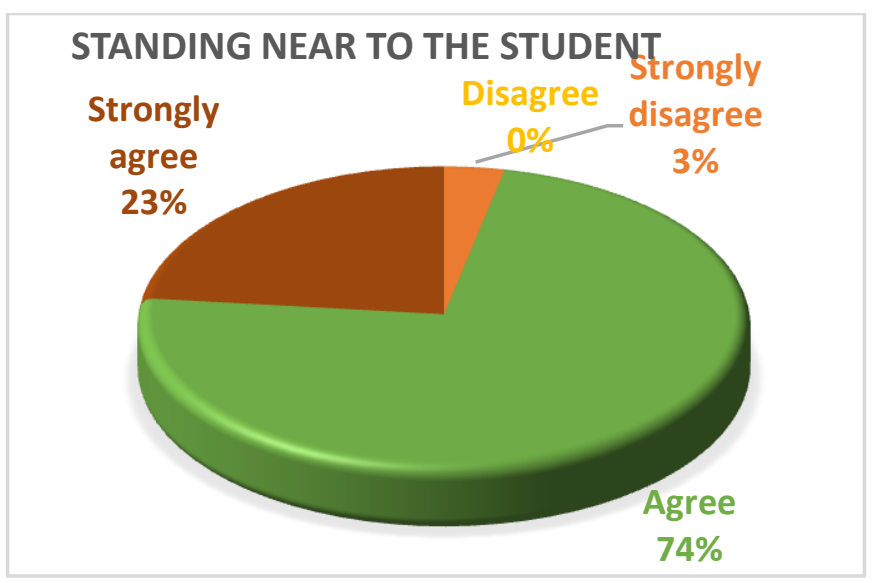

Source: Field Data 2018 
$23 \%$ of teachers strongly agreed and $74 \%$ of teachers agreed in standing near to the student increases the desirable behavior high in the academic performances while $3 \%$ of teachers disagreed. In the overall perspective, most of the teachers agreed with this statement.

The researcher found there are 7 techniques under social reinforcement. In the holistic view of social reinforcement, most of the teachers agreed that using social reinforcement techniques increases the desirable behavior high in the academic performances.

\subsection{Conclusion}

This part discussed the identification of positive reinforcement techniques and their effectiveness. The positive reinforcement was divided into five types and each time the techniques were identified. From the identified technique the researcher analyzes their effectiveness. In sensory reinforcement, natural reinforcement, material reinforcement, and social reinforcement most of the teachers accept that using techniques from sensory reinforcement increase the student's desirable behavior high in academic performances. In generalized reinforcement, two techniques were agreed upon by most of the teachers, and two techniques were disagreed with by most of the teachers.

\subsection{Issues Related To Positive Reinforcement Techniques And Social Work Interventions.}

The issues related to positive reinforcement techniques and social work interventions were analyzed in three themes.

They are individual, group, and system level.

\subsubsection{Individual Level Issues}

- Lack of skills and training in positive reinforcement application

'The teachers in schools are not very much familiar with the concept of positive reinforcement and some teachers don't know the term positive reinforcement' (Key informant)

According to (C.D, 2003) the effectiveness of using reinforcement is determined by how it is delivered by the teacher and perceived by the students. It means that the teacher should have clear goals for giving reinforcement to the students. When the teacher does not have the idea of the reinforcement it affects the effectiveness of the teaching and the student as well.

- Lack of talents in improving teaching methodology

'There are many ways to teach for the primary student. But here, the teachers are stick in one method of teaching' (key informant)

According to the key informant, there are many teaching methods to teach the students. But most of the teachers use the traditional methods. They practice in one method and they adopt that. Through this the teacher also gets bored and the student also gets bored.
- Lack of awareness related to specific reinforcement strategies

There are many ways to give a reinforcement, but teachers don't aware of that. For example, we can use one reinforcement technique instead of another (key informant)

According to the key informant the teachers are having lack awareness regarding positive reinforcement strategies.

- Lack of knowledge of the theory of positive reinforcement

The concept of positive reinforcement is discussed in the teacher's educational curriculum. But the practice and the application are less in the schools.

'We teach the students about positive reinforcement. But not in in-depth manner' (key informant)

- Lack of awareness regarding concept formation on the child

Primary teachers are working with the 6-10 age group. According to Jean Piaget's cognitive development theory at the age of 2-7 children begin to think symbolically and learn to use words and pictures to represent objects. Children at this stage tend to be egocentric and struggle to see things from the perspective of others. While they are getting better with language and thinking, they still tend to think about things in very concrete terms. At the age of 7-11 children begin to thinking logically about concrete events. They begin to understand the concept of conservation; that the amount of liquid in a short, wide cup is equal to that in a tall, skinny glass, for example. Their thinking becomes more logical and organized, but still very concrete. Children begin using inductive logic, or reasoning from specific information to a general principle. When a teacher fails to know the concept formation of the student, it affects the selection of reinforcement strategies appropriate for grades.

- Unable to differentiate the qualities of urban, rural, and non-urban communities.

According to the person and environment, the theory states that a person's behavior can largely be understood by looking at their environment, including their past environment. The qualities of the environment influence the person's behavior. The urban, rural, and non-urban communities are different from one to one. When some teacher from urban area teaches in the rural area they fail to differentiate the qualities of the area.

'When transferring the teacher from urban to rural schools some teachers unable to accept the students. This is the main attitude where the teachers want to change' (key informant)

- $\quad$ Lack of understanding in childhood disorders.

Some students can be with childhood disorders. For example, ADHD, mild level autism, and impairment of motor skill development. These students need special attention than other 
students. When the teacher was unable to find student's problems, they fail to get the total outcome of the technique.

- Using different positive reinforcement confuses the child

'There are many positive reinforcement techniques. When a teacher uses more than four techniques the students get confused and they unable to adapt the technique' (Key informant)

According to the statement by using different reinforcement techniques students get confused and unable to adopt the flow of teaching.

- Students deviating from the academic interest because of the unequal treatment

'When the teachers give material for the performing student, some students can get upset easily' (Key informant)

From this statement, by using the material things the other students can feel unequal treatment in the same class. This can cause ignorant behavior and deviating behavior from the student.

- Less ability to use the technologies in teaching

'There are many teaching tips on the internet. But the teachers don't show interest to learn those thing' (Key informant)

From this statement, the limited number of teachers in the research area are using the technologies for teaching.

- Less focus on activity-based teaching

'Nowadays parents and teachers are running behind the marks. They push the student to score marks in the primary setting. Due to this, the student, teacher, and parents get unwanted pressure' (Key informant)

According to the key informant statement the most of the teachers and parents pushing the student to get more marks in the primary. When pushing the student to earn marks he can have the chance to lose the childhood pleasures. It will affect the future life of the particular student.

- Lack of skills in identifying student's problem

According to the key informants, teachers having lack skills in identifying the student's problem. Because they blame the student and the student's family background. Rather than focusing on them they blaming the environment of the student.

'Most of the teachers blame student and the student's family background rather than focusing themselves' (Key informant)

- Older teachers have chronic diseases such as blood pressure and diabetes.

There are several elder female teachers are there. They are with a variety of diseases. They come to the class and show their vulnerability to the students. They are the people who punish the students by scolding badly' (Key informant)

From the key informant statement, there are many elder teachers in primary units. Scientific studies show that due to the blood pressure the tension and the aggressive feeling can be increase. In this situation, the teachers show their vulnerabilities to the students. It will affect the use of positive reinforcement and motivation.

\subsubsection{Individual-Level Social Work Interventions}

- Training for the teachers about positive reinforcement techniques

'Teachers need more training in the techniques about positive reinforcement' (Key informant)

According to the key informant's opinion, the social work intervention can be done by giving training on positive reinforcement techniques for the teachers in the research area.

- Material reinforcement can be reform by other reinforcement

'Due to the unequal treatment of material reinforcement students can deviate from the academic performances' (Key informant)

To prevent this issue aware the teachers regarding the reforming positive reinforcement techniques instead of material reinforcements.

- Limiting the parental influence in teachers' teaching methodology

'Parents often influencing in the teaching method of the teachers and due to this they are getting confuse' (Key informant)

From this statement, teaching methods are influenced by the parents in the schools. Due to this the teaching methodology also getting affect. Therefore the parental influence can be limit in the Primary sections.

- Aware the teachers regarding the concept formation of the children.

- The resource mobilization and the outside resources can be addressed by the social worker in the particular community.

The existing resources can be identified by the school social worker and the mobilization can be performed in the school setting.

- Appreciate equally for the students

Through some reinforcement techniques, students get mentally disturbed and deviating themselves from academic performances. To ignore this situation the students can be equally rewarded or other reinforcement techniques can be used together. 


\subsubsection{Group-Level Issues}

- Lots of students in the primary classroom

According to the Ministry of Education Sri Lanka under Supreme Court case number 289/2007 the maximum number of children that should be in grade one class of government schools to be 35 from the year 2016. According to this statement, there should be 35 or less than 35 students who want to be in a classroom. These 35 students are managed by one teacher in the primary education unit. When comparing to the foreign countries there are less than 20 students in the classroom.

'When comparing Sri Lanka to other countries, our primary education system has more students. This can affect the teaching. Because due to more students teachers can face problems of controlling students. Here, use of positive reinforcement technique also getting affected.' (Key informant)

- Practice traditional teaching in the classroom

'The new educational curriculum for primary students suggests using the joyful teaching method. But this implementation is lacking in the classroom and the teachers practicing traditional methods' (Key informant)

According to the key informant most of the teachers using the traditional method (Marks-oriented Method). A very typical feature of traditional methodology, as Broughton and his colleagues claim, is the "teacher-dominated interaction". Through teacher-dominated interaction the students unable to enjoy the learning. At this time the effectiveness of the reinforcement will be down.

- Teachers and students exist in urban schools and a limited number of students and teachers are in rural and nonurban schools

'There are more teachers and more students are in urban schools. But in another area, one or two teachers are there for the whole primary unites.' (Key informant)

According to this statement, there are more teachers and students in urban schools and fewer teachers and students in rural and non-urban areas.

- Inter conflict affects the whole education for the students

'When a teacher gets conflict with other teacher or principal, sometimes she ignores to teach to the students. This affects the student's education and motivation' (Key informant)

According to the statement, the inner conflict in the school affects the students. This belongs to the teacher's attitude.

- Elder teachers are more than young teachers

- Female teachers are more than male teachers

'In overall perspective, the ratio of a female teacher and male teacher is 80:20'. (Key informant)
From the above statement, there are more female teachers are there in the primary unit.

- Private tuition classes are influencing in negatively the reinforcement

'Normally students start to go to private tuitions in the grade of two. If a teacher practice reinforcement techniques for the students, it can be disturbed by the private tuition classes. Sometimes they can lose interest in the particular technique.' (Key informant)

According to this statement, the private tuition classes disturbing the positive reinforcement technique use by the teacher in the school.

\subsubsection{Group-Level Social Work Interventions}

\section{- Change the traditional teaching method}

Social work intervention can be in changing the traditional method and implement the climate-friendly teaching method. This can be addressed by the school social workers.

- Create a common network to review the updates in the teaching methodology

The social worker can create a common platform to review the updates regarding teaching methodology in the area. Through this, the updates and publications regarding positive reinforcement can be easily referred to by the teachers.

- Empower the counselling and leadership programs for teachers

Here, in the leadership and counselling program, the concept of reinforcement can be educated. Through this, the teacher can deal with the students effectively.

- More young teachers can be intake in the primary units

To eliminate the problem of showing vulnerabilities towards the students, younger teachers can be inclusive in the primary unit.

- An equal amount of students want to be added in urban, rural, and non-urban areas

Because there is an unequal intake in the urban schools. This can be stopped and the social workers advocate to implement equal treatment.

\section{- Private tuitions want to be limit by grades}

Social workers can advocate against the negative impact of the private tuition classes and the later impacts on the child's life.

- Facilitate the training programs related to positive reinforcement techniques

The social worker can find out the organizations which functioning in the area and conduct programs relevant to the problems and issues. 


\subsubsection{System-Level Issues}

- No evaluation methods to measure the students' performances

'In the education department, there is an evaluation form to measure the teachers. But there are no evaluation criteria to measure the students' (Key informant)

According to the key informant's statement, there is no evaluation method to measure the students. When they don't measure the student's performances they can't unable to see whether the student is motivated to study or not.

\section{- Same evaluation method for the teachers}

The key informant said, that there are the same evaluation criteria for the secondary and primary units. There is no specific area asking about the reinforcement application.

'There is no any area describing positive reinforcement techniques in the evaluation sheet of the teachers' (Key informant)

\section{- Less resource in rural and urban schools}

'There is no enough facility to apply some reinforcement techniques for the students' (Key informant)

From this statement, there is no enough facility to use the modern reinforcement techniques.

- NIE system doesn't implement in the schools properly

There are many programs and update information conduct by the NIE to teachers, but they don't use that information to the students. They stick into one teaching method' (Key informant)

According to the respondent the National Institute of Education's programs and the given knowledge are not using by teachers.

\section{- Primary teachers inclusive qualification wants change}

'Nowadays the primary teachers are getting intake with a diploma. But some schools take teachers without qualifications in primary special. When they take those teachers they don't feel the importance of primary education and the motivation methods' (Key informant)

From this statement, the key informant said that the primary teachers want to intake with the special qualification in primary education.

- A limited number of Professionals in the primary department in Batticaloa.

'There are 3 In-Service Advisers and $1 A D$ in the primary unit if Manmunai North'. (Key informant)

- Lack of NGO in the Districts

3.7.6 System-Level Social Work Interventions

- History model can be implemented in the schools
'History model has the whole details about the student and it maintains in grade by grade. Through seeing the history of the student, we can see the improvement, problems, disease, environment, etc.' (Key informant)

According to (Mills, 2015) academic performance records, such as grades and report cards, provide insight into student progress and help parents and teachers make important decisions regarding students' learning needs. Attendance records help teachers and school staff maintain accountability for students' safety. Behavior records are useful for parentteacher conferences and disciplinary meetings. Therefore maintaining a historical record is needed. Through maintaining the history report the teacher can able to understand the proper positive reinforcement technique according to the student's interest.

- Evaluation methods want to separate to primary teachers and include the area of motivation or reinforcement techniques

When the evaluation sheet consists of the positive reinforcement application teachers would know and get awareness regarding that.

\section{- $\quad$ Core-teaching can be practice in the zone}

'In some schools in Colombo, they adopt the core teaching method. It means there are 2 teachers in the classroom. When one teacher teach another teacher observe' (Key informant)

- Theories and application part should be in-depth in the field of Primary Education

'We are developing in-depth criteria on positive reinforcement for the students who take the Education as a special subject' (Key informant)

- Make policies to reduce the intake number of primary student

Research studies show that the average student number in a primary class is 20 to 24 . Therefore the social workers can address the issues and limit the number of students.

- Primary teachers want to intake with the qualification special in Primary education.

Social workers can address this issue and advocate the negative impacts of these criteria.

\section{DISCUSSION AND SUGGESTION OF THE STUDY}

The purpose of the discussion is to interpret and describe the significance of the findings in light of what was already known about the research problem being investigated and to explain any new understanding or insights that emerged as a result of the study of the problem.

According to (Maag, 2001 January 01), "when an educator says, "I've tried positive reinforcement and it doesn't work," that statement is an oxymoron because if a consequence did not function to increase a behavior, then it was not 
reinforcement'. Teachers are constantly searching for ways to improve students' performance. The technique of rewarding students for their work gives a better academic performance. (Nelsen, n.d.) Emphasizes "the importance of positive reinforcement is not only creating clear rules but of making them fair. Any rule should be followed by the parent or teacher (as much as possible), as well as by the child". Using positive reinforcement techniques in the classroom with the students helps to develop their instinct motivation. According to the instinct theory of motivation, all organisms are born with innate biological tendencies that help them survive. This theory suggests that instincts drive all behaviors. Intrinsic motivation is the motivation drawn from internal sources, it makes to feel good about oneself. This motivation makes the student get self-desired to seek new things and new challenges. It gives the enjoyment or interest rather than external pressure from parents, teachers, or others. Students who are intrinsically motivated are more likely to engage in the task willingly as well as work to improve their skills, which will increase their capabilities. It motives the students to engage in the classroom activity energetically and makes way to engage in the self-learning activities as well.

This positive reinforcement helps the students to overcome the challenging behavior in the classroom. According to the challenging behavior foundation, they define the challenging behavior "Culturally abnormal behaviors of such an intensity, frequency or duration that the physical safety of the person or others is likely to be placed in serious jeopardy, or behavior which is likely to seriously limit the use of, or result in the person being denied access to, ordinary community facilities." There are lots of things in the environment (stimuli) that can affect behavior. Using positive reinforcement techniques in the classroom helps to increases the probability of a behavior happening again. (Axelrod, 1996) Recommended that "technique based on positive reinforcement have a tremendous impact on managing student's challenging behavior". When the teacher applies positive reinforcement techniques in the classroom students can able to get motivation from withdrawal behavior such as shyness, laziness, and withdrawal from academic performances. Through these positive reinforcement techniques, students can able to develop theirs interpersonal and intrapersonal development. Interpersonal development such as being in a happy mood, becoming an active listener in the classroom, asking the question and involving actively in the activities. Intrapersonal development such as creative thinking, involving activities with curiosity, and getting energy to create a relationship with other classmates. Positive reinforcement techniques in the classroom applied by the teacher help the students to encourage to overcome inappropriate social behaviors. Inappropriate behavior is the least offensive of the disruptive behaviors and is often seen as the way a person "broadcasts" him or herself. It can be stealing, disturbing behavior, being over affectionate with other students, and inappropriate conversations with each other.
In the field of social work, the study regarding positive reinforcement techniques is important. Because school social workers work with the parents, students, and teachers to identify the needs which interfere with learning and work with students to get the services they need. Social workers work with the general and special education students and their families to resolve their emotional, behavioral, and social problems. Through identifying the positive reinforcement technique, it can shape the behavior of the children in schools as well as in family also. The need of applying positive reinforcement techniques can influence the students' behavior in schools. This can be aware by the school social worker to school, home, and community. By applying the positive reinforcement techniques for the students, the school social worker can get some special case references from the teacher. This helps the school social worker to do case works as well as group works also. By engaging in this research study the school social worker able to facilitate the teachers to identify and apply positive reinforcement for the students in primary education. Through this, the primary education unit can have a positive and sustainable change in the student's academic performances. School social workers can promote the positive reinforcement technique and its needs to the micro, mezzo, and macro level. It can lead to finding out the hybrid mixture of the explanatory model.

\subsection{Discussion of the Findings}

The researcher has round the specific techniques which teachers use in the classroom setting. These techniques were divided into Sensory reinforcement, Natural reinforcement, Material reinforcement, generalized reinforcement, and social reinforcement.

The classification of the techniques are in table number 02

$$
\text { Table Number } 02
$$

(Field Source 2018)

\begin{tabular}{|c|c|c|c|c|c|}
\hline No & Findings & $\begin{array}{c}\text { Strongly } \\
\text { Disagree }\end{array}$ & Disagree & Agree & $\begin{array}{c}\text { Strongly } \\
\text { Agree }\end{array}$ \\
\hline 1 & $\begin{array}{c}\text { Positive } \\
\text { reinforcement } \\
\text { increases the } \\
\text { desirable behavior }\end{array}$ & $\begin{array}{c}\text { Using different } \\
\text { positive } \\
\text { reinforcement } \\
\text { techniques are } \\
\text { helpful in teaching }\end{array}$ & & $100 \%$ \\
\hline \multicolumn{5}{|c|}{ Sensory Reinforcement } & $100 \%$ \\
\hline 3 & $\begin{array}{c}\text { Touching and } \\
\text { playing with clay }\end{array}$ & & $13.3 \%$ & $33.3 \%$ & $53.4 \%$ \\
\hline 4 & $\begin{array}{c}\text { Touching and } \\
\text { playing with } \\
\text { building blocks }\end{array}$ & $6.7 \%$ & $23.3 \%$ & $70.0 \%$ \\
\hline 5 & $\begin{array}{c}\text { Allowing to hear } \\
\text { recorded stories }\end{array}$ & & $30.0 \%$ & $33.3 \%$ & $36.7 \%$ \\
\hline 6 & $\begin{array}{c}\text { show cartoons and } \\
\text { videos }\end{array}$ & $6.7 \%$ & $20.0 \%$ & $33.3 \%$ & $40.0 \%$ \\
\hline 7 & blow bubbles & $3.3 \%$ & $30.0 \%$ & $66.7 \%$ \\
\hline \multicolumn{5}{|c|}{ Natural Reinforcement } \\
\hline
\end{tabular}




\begin{tabular}{|c|c|c|c|c|c|}
\hline 8 & $\begin{array}{l}\text { Play in classroom } \\
\text { or ground }\end{array}$ & & & $23.3 \%$ & $76 / 7 \%$ \\
\hline 9 & $\begin{array}{c}\text { Erase the black } \\
\text { board }\end{array}$ & & $3.3 \%$ & $23.3 \%$ & $73.4 \%$ \\
\hline 10 & $\begin{array}{l}\text { being the person } \\
\text { who does minor } \\
\text { works teacher } \\
\text { says }\end{array}$ & & $13.3 \%$ & $46.7 \%$ & $40.0 \%$ \\
\hline 11 & $\begin{array}{l}\text { Sitting near to a } \\
\text { favorite friend }\end{array}$ & $3.3 \%$ & $16.7 \%$ & $40.0 \%$ & $40.0 \%$ \\
\hline 12 & Read story books & 3.3 & $23.3 \%$ & $46.7 \%$ & $26.7 \%$ \\
\hline \multicolumn{6}{|c|}{ Material Reinforcement } \\
\hline 13 & Stickers & & & $40.0 \%$ & $60.0 \%$ \\
\hline 14 & Clay & & $6.7 \%$ & $30.0 \%$ & $63.3 \%$ \\
\hline 15 & Pencils & & $23.3 \%$ & $53.4 \%$ & $23.3 \%$ \\
\hline 16 & Copies & & & $46.7 \%$ & $53.3 \%$ \\
\hline 17 & Erasers & & & $46.7 \%$ & $53.4 \%$ \\
\hline 18 & Toffees & & $26.7 \%$ & $33.3 \%$ & $40.0 \%$ \\
\hline 19 & Sharpeners & $3.3 \%$ & $10.0 \%$ & $33.3 \%$ & $53.4 \%$ \\
\hline \multicolumn{6}{|c|}{ Generalized Reinforcement } \\
\hline 20 & Tokens & $6.7 \%$ & $50.0 \%$ & $33.3 \%$ & $10.0 \%$ \\
\hline 21 & Credits & $26.7 \%$ & $70.0 \%$ & $3.3 \%$ & \\
\hline 22 & Points & $13.3 \%$ & $26.7 \%$ & $40.0 \%$ & $20.0 \%$ \\
\hline 23 & $\begin{array}{l}\text { Marking V.Good } \\
\text { in red pen }\end{array}$ & & & $26.7 \%$ & $73.3 \%$ \\
\hline \multicolumn{6}{|c|}{ Social Reinforcement } \\
\hline 24 & A simple smile & & & $36.7 \%$ & $63.3 \%$ \\
\hline 25 & A look & & $3.3 \%$ & $43.3 \%$ & $53.4 \%$ \\
\hline 26 & $\begin{array}{l}\text { Naming the } \\
\text { student }\end{array}$ & & $3.3 \%$ & $36.7 \%$ & $60.0 \%$ \\
\hline 27 & $\begin{array}{l}\text { Saying goods in } \\
\text { front of the } \\
\text { parents }\end{array}$ & & & $33.3 \%$ & $66.7 \%$ \\
\hline 28 & $\begin{array}{c}\text { Pinching the } \\
\text { cheeks }\end{array}$ & & $13.3 \%$ & $46.7 \%$ & $40.0 \%$ \\
\hline 29 & Small wink & & $16.7 \%$ & $53.3 \%$ & $30.0 \%$ \\
\hline 30 & $\begin{array}{c}\text { Standing near to } \\
\text { the student }\end{array}$ & $3.3 \%$ & & $73.4 \%$ & $23.3 \%$ \\
\hline
\end{tabular}

All of the respondents $100 \%$ agreed in positive reinforcement increase the desirable behavior and using different positive reinforcement techniques are helpful in teaching. From this agreement, the teachers in Batticaloa district are known about positive reinforcement and its' impact.

In the sensory reinforcement techniques, most of the teachers agreed in using sensory reinforcement techniques such as touching and playing with the clay, touching and playing with the building blocks, allowing them to hear recorded stories, allowing them to see cartoons and videos, and allowing them to blow bubbles increase the desired behaviors in the academic performances of the primary students. In the Natural reinforcement, most of the teachers agreed in using natural reinforcement techniques such as make them play in the classroom or ground, make them erase the blackboard, being the person who does minor works which teacher says, make them to sitting near to the favorite friend and allow them to read storybooks increase the desirable behavior high in the academic performances of the primary students. In material reinforcement, most of the teachers agreed in using material reinforcement techniques such as giving stickers, giving clay, giving pencils, giving copies, giving erasers, giving toffees, and giving sharpeners increase the desirable behavior high in the academic performances of the primary students. In generalized reinforcement, most of the teachers agreed in using generalized reinforcement techniques such as giving points and marking v.good in red pen increase the desirable behavior high in the academic performances of the primary students, and most of the teachers disagreed in giving tokens and giving credits increase the desirable behavior high in the academic performances of the primary students. In social reinforcement, most of the teachers agreed in social reinforcement techniques such as a simple smile, a look, naming the particular student, saying goods in front of the parents, pinching cheeks, a small wink, and standing near to the student increase the desirable behavior high in the academic performance of the primary students.

The issues related to promoting positive reinforcement techniques and the social work interventions were divided into 3 themes. They are individual-level issues and interventions, group-level issues and interventions, and system-level issues and interventions.

The researcher found the issues under individual level are lack of skills and training in positive reinforcement application, lack of talents in improving teaching methodology, lack of awareness related to specific reinforcement strategies, lack knowledge on the theory of positive reinforcement, lack awareness regarding concept formation of on children, unable to differentiate the qualities of urban, rural and non-urban communities, lack understanding in childhood disorders, using different positive reinforcement techniques confuse the child, students deviating themselves from the academic interest because of the unequal treatment, less ability to use the technologies in teaching, less focus on the activity-based teaching, lack skills in identifying the problem of students and elder teachers have chronic diseases such as blood pressure and diabetes.

The interventions at the individual level such as training for the teachers about positive reinforcement techniques, material reinforcement can be reform by other reinforcement techniques, limiting the parental influence in teacher's teaching methodology, make the teachers appreciate equally for the students, aware the teachers regarding the concept formation of the children and resource mobilization and the outside resources can be addressed by the social worker in the community.

The issues under group level are lots of students are in one primary classroom, teachers practice the traditional teaching model, teachers and students are exist in the urban schools and 
limit number of students and teachers are in rural and nonurban schools, inter conflict of teachers affects the whole education of the students, elder teachers are more than youth teachers, female teachers are more than male teachers and private tuition classes are influencing negatively in the reinforcement.

The interventions at the group level such as changing the traditional model, create a common network to review the updates in the teaching methodology, empower the counselling and leadership programs for the teachers, more young teachers can be intake in the primary unites, an equal amount of students want to be added in rural, urban and nonurban areas, private tuition classes want to limit by grade and facilitate the training programs related positive reinforcement techniques.

The issues under system level are no evaluation methods to measure the students' performances, the same evaluation method for the primary and secondary teachers, fewer resources in the rural and non-urban schools, NIE system doesn't implement in the schools properly, primary teachers inclusive qualification wants to change, the limited number of professional in primary units and lack of Non-Governmental Organizations in the district.

The system-level interventions can implement a history model in the primary schools, evaluation methods want separate to primary and include the area of motivation or reinforcement, the core-teaching method can be practice in the zone, theories and the application about positive reinforcement can be indepth in the field of primary education, can make policies to reduce the number of primary students in Sri Lanka and primary teachers want to intake with the qualification special in primary education.

According to the theory of reinforcement, it focuses on observable behavior rather than needs theories that focus on personal states. Reinforcement theory is a form of operant conditioning and focuses on the environmental factors that contribute to shaping behavior. Simply, reinforcement theory claims that stimuli are used to shape behaviors. Positive reinforcement uses the reward system. The reward system is a collection of brain structures that attempt to regulate and control behavior by inducing pleasurable effects. Here, through the finding, the techniques from sensory, natural, material, generalized and social are giving pleasurable effects to the brain and increase the student's desirable behavior.

In the effectiveness of the techniques, most of the teachers are agreed in the reinforcement techniques from sensory, natural, material, social is increasing the desirable behavior of a primary student other than two techniques from generalized reinforcement. The two techniques are giving tokens and giving credits to the students.

Even though most of the teachers are agreed on positive reinforcement techniques increase the desirable behavior high, there are some issues to implement those techniques in the application. These issues were discussed in the above section.

\subsection{Suggestions}

In this part, the researcher will discuss the models and suggest a new explanatory model practice in school social work. The hybrid Choice Model (HCM) can be viewed as an expanded discrete choice modeling framework, which integrates different types of models into a single structure that is estimated simultaneously (Ben-Akiva M, 2002).

The selected models are,

\section{Reinforcement model by Katy Tynan (2015)}

The Reinforcement Model refers to positive reinforcement, not negative. The key difference being that positive reinforcement presents a rewarding stimulus to a learner after a behavior is completed. Negative reinforcement removes a positive stimulus when negative behavior is expressed (Tynan, 2017). This model has main four practices. They are,

\section{Personalization}

Praise is a common stimulus used in positive reinforcement. For learners, it's most potent in personalized form. Though praising an entire group works, focusing on specifics, and zeroing in on exactly what an individual has done well works best.

\section{Immediate Rewards}

For The Reinforcement Model to be effective, the reward stimuli must be given immediately after the desired behavior occurs. There must be a strong correlation built between the specific, desired action and the reward so that learners can create a strong link in their minds.

\section{The Element of Surprise}

The quickest way to dull the effectiveness of The Reinforcement Model is to use rewards so often that they come to be expected. The element of surprise is motivating, and well-considered rewards and praise are more meaningful. Once a learner expects the reward, it becomes less motivating.

\section{The Drive of Recognition}

Humans love competition, it's exciting, invigorating, and engaging. People are motivated by excelling in anything and even more motivated by being recognized and appreciated for excelling. Creating a secondary source of recognition and appreciation through reward systems or leader boards adds another level of motivation to learners.

With the above four practices and positive reinforcement techniques from sensory, natural, generalized, material, and social reinforcements together the child can bale to motivate and perform well. 
The social interaction model (Kumar, 2017)

This model is based on the ecological systems theory which was developed by Frey and Dupper (2005) and Germain (2006). This model promotes the view of the individual and environment as a unified interacting system in which each constantly affects and shapes the other. This model attends to the complexities of the environment and the person by engaging progressive forces in people and removing the environmental obstacles for promoting growth and adaptive functioning. The role of school social workers is an everexpanding domain that is further affected by the knowledgebase, recognition of opportunities to address the level of student needs.

The reinforcement model suggests positive reinforcement to promote positive behavior through four practices. The social interaction model emphasis to get the adaptive functioning of the individual through engaging in reformist powers and eliminate the conservational barriers.

The researcher suggests a Hybrid Choice Model (HCM) named, Positive Social Interaction Reinforcement model which is formulated from the reinforcement model and social interaction model. The Positive social interaction reinforcement model discussed the reinforcement techniques from sensory, natural, material, generalized and social, and through mixing these techniques and applying them, the student can get a fruitful consequence progressive force to the growth which showed in bellow.

Positive Social Interaction Reinforcement Model (2019)

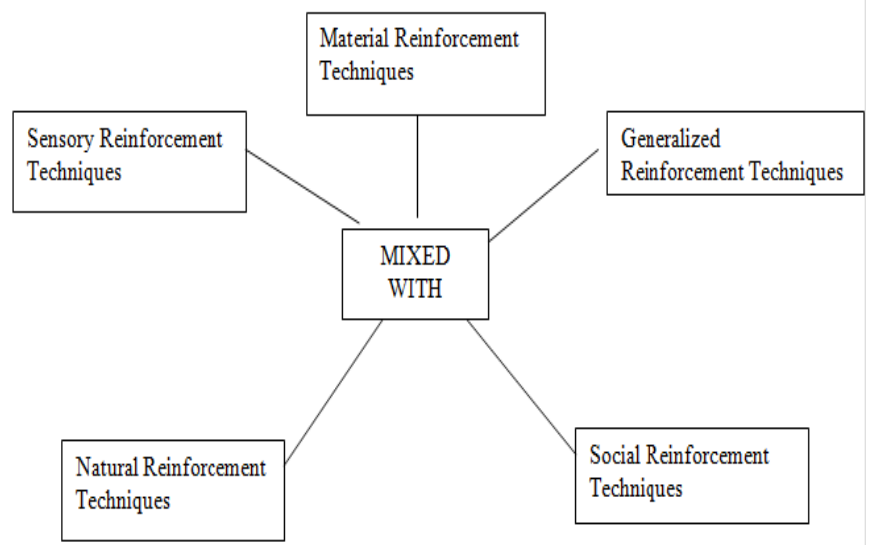

Justification of the Positive Social Interaction Reinforcement Model

The reinforcement model explains, rewarding stimuli to a learner after a desirable behavior is presented. This practice can be in 4 forms. In personalization, praise is the common stimuli. Through praising the student the motivation can happen. Here, motivation is the factor that gives the stimuli to the particular student. In an immediate response, the rewards must be given without any delay. When it gets too delay the student can lose interest in reinforcement. An element of surprise, the particular reward technique should give unexpectedly. It helps to motivate the student meaningfully. In the dive of recognition, the reward should present with a sense of love and the reward could be appreciated for the positive feeling.

In the positive social interaction reinforcement model, by mixing the techniques from sensory reinforcement, social reinforcement, natural reinforcement, material reinforcement, and generalized reinforcement and applying according to student's interest, it can able to full fill the practice of reinforcement model. Because most of the teachers agreed in using positive reinforcement techniques increases the desired behavior in the academic performances.

In Social interaction model, it unifies the interacting system of the environment and the individual. The environment affects and shapes the interaction of the individual. The main concept of this social interaction model is, through progressive force in the people and removing obstacles in the environment, an individual can grow and adopt functioning in the environment.

The progressive force can be stimulated by the use of positive reinforcement techniques. Because a child who is intrinsically motivated performs a task because of the joy that comes from learning new materials. A child who performs in school to gain parent approval, grades, or rewards is externally motivated. While research shows that those children with internal motivation may achieve greater success, teachers and parents often find that many children seek external reinforces. (OnLine, 2002).

The progressive force can be filled by applying positive reinforcement techniques together according to the student's interest. The progressive growth helps the student to overcome the obstacles in the environment. By applying the positive social interaction reinforcement model for the students, the students can able to overcome the environmental obstacles such as changing the improper and maladaptive behavior into desirable behavior and the student can able to get constructive structural and pragmatic change in the future. This model helps the teacher to give motivation and encouragement by using varieties of techniques from positive reinforcement and aware the teacher of the concept of positive reinforcement and its application.

Therefore by applying Positive Social Interaction Reinforcement Model a student can get progressive force and removing obstacles from the environment. It makes the student get growth and adoptive function from the environment. The validation of the Positive Social Interaction Reinforcement Model (2019) was shown in bellow. 


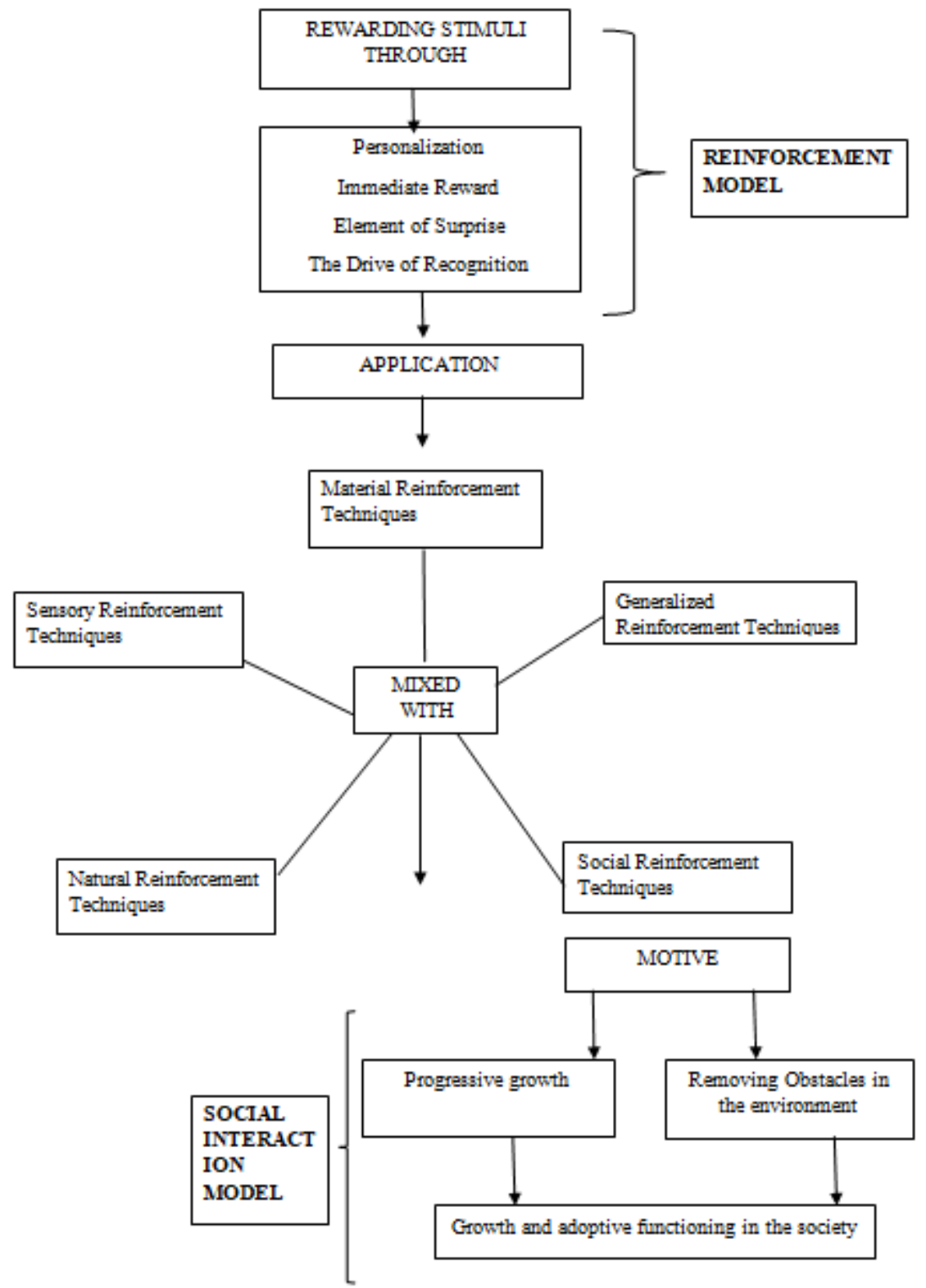

The effectiveness of the positive reinforcement is determined by how it is delivered by the teacher and perceived by the students. The findings underscore that the teacher should have clear goals on giving reinforcement for the students and using different positive reinforcement techniques are helpful in the teaching.

The reinforcement is given based on the students' behavior to reinforce them to repeat the wished behavior. By applying positive reinforcement techniques to the students, they can able to get motive in performances. This motivation helps to lead to good academic performances in their later life.

\section{CONCLUSION AND RECOMMENDATIONS}

This is the main gap between the teachers and their positive reinforcement technique's application. The need for positive reinforcement occurs when the child needs verbal affirmation.
It is a simple way of encouragement. When the child puts the effort into doing something he needs that work to be appreciated by the teacher. It gives the child to strive to do things more. Through this, the child can develop intrapersonal development. The selected positive reinforcement technique should apply equally among the children. If this condition fails, it makes way to think inferior by comparing other children in the classroom and marginalize them from other children.

Students who are intrinsically motivated are more likely to engage in the task willingly as well as work to improve their skills, which will increase their capabilities. It motives the students to engage in the classroom activity energetically and makes way to engage in the self-learning activities as well. Therefore need of identifying positive reinforcement techniques are important in school settings. 
In this study, the recommendations are focusing to minimize the issues from promoting positive reinforcement applications. Through minimizing the identified issues the positive reinforcement techniques can be applied in the school settings.

The recommendations such as,

\section{- Appointment of the school social workers in Batticaloa district}

There are no school social workers in the Batticaloa district. According to the National Institute of Social Development at present, there are about 1500 social workers trained by the Sri Lanka School of Social Work. The role of the social worker is to intervene in the crises of human interactions to find out solutions for the problems faced by the people for their well-being. The problems could be located with individuals, families, groups, and communities. They could be related to the lack of availability of service delivery systems or the absence of social policies. The social worker identifies the service and enhances the individual and community wellbeing.

School Social Workers are the link between the home, school, and community in providing direct as well as indirect services to students, families, and school personnel to promote and support student's academic and social success. But in the Batticaloa district, there are no school social workers.

\section{- Implementation of the historical model in the schools in Batticaloa}

According to (Mills, 2015) academic performance records, such as grades and report cards, provide insight into student progress and help parents and teachers make important decisions regarding students' learning needs. Attendance records help teachers and school staff maintain accountability for students' safety. Behavior records are useful for parentteacher conferences and disciplinary meetings. Therefore maintaining a historical record is needed. By maintain the whole record of the student, the teacher can see the progressiveness step by step.

By implementing this model in this study area, the teachers can have a clear picture of the particular student. The history model helps to review the answers from the whole aspects of the student.

\section{- $\quad$ The core-teaching method can be practice in the teaching}

Core teaching means the combination of two or three teachers in one classroom. In Sri Lanka, the maximum number of the student in one primary classroom is $35-37$. It is very difficult for one teacher to manage the whole class. Therefore, if the core teaching method is applied, the teacher can minimize the burden and increase the observation of the students. It helps to identify the student's best interest technically.

- Improve policies to minimize the student's number in the classroom
When comparing to the developed country the maximum number of students in one classroom is 18-24. But in Sri Lanka, there are 35-37. When the number increases the way of controlling the students also increases. It will lead to the problem physically and mentally. Therefore, a social worker can make policies to reduce the number of students in the primary classroom

\section{- Maintaining training in positive classroom management}

The teaching training and the update methodologies were trained by the professionals in the primary unit. But according to the data, there are a limited number of professionals and limited training have taken palace. Therefore the social worker can facilitate the training by co-ordinating from different organizations.

\section{- Action Research can be done and publish by teachers}

Action research is conducted in the field of education. By involving in the action research teachers investigate their practice in new ways, looking deeper into what they and their students do and fail to do, teachers develop a deeper understanding of students, the teacher learning process, and their role in the education of both teachers and students will increase.

Action research is an ongoing process and its' strategies can be widely applied. Therefore, action researches can be done and published.

\section{- The inclusive primary teachers' qualification wants change}

In some schools in Batticaloa, the teachers are intake with the diploma non-relevant to the primary education. For example, some fewer teachers got a special qualification in primary education. Therefore this problem should be an advocate by a social worker and the criteria want to change.

\section{REFERENCES}

[1] Axelrod, S. (1996). What's Wrong with Behavior Analysis? Journal of Behavioral Education, 247-256.

[2] Ben-Akiva M, M. D.-s. (2002). Hybrid choice models. Progress and challenges, 163-175.

[3] C.D, W. B. (2003). Using Rewards to Teach Students with disabilities. Remedial and Special Education, 88-86.

[4] Committee, K. R. (2007, January). The Importance of Play in Promoting Healthy Child Development and Maintaining Strong Parent-Child Bonds. Retrieved from Pediatrics publications: http://pediatrics.aappublications.org/content/119/1/182

[5] Copple, S. B. (1997). Developmentally appropriate practice in early childhood programs serving young children. Washington, DC: NAEYC.

[6] Cotton, C. (2006). Class Reinforcement. USA: University of Illinois.

[7] Horcones, C. L. (1992). Natural Reinforcement: A Way To Improve Education. Applied Behaviour Analysis, 71-75.

[8] John M. Dudley, G. G. (2006). Research Design. Research Gate.

[9] Kumar, D. C. (2017). School social work: An emerging area of professional. International Journal of Applied Research, 1247.

[10] Maag, J. W. (2001 January 01). Rewarded by Punishment: Reflections on the Disuse of Positive Reinforcement in Schools. The University of Nebraska-Lincoln. 
[11] Mills, S. (2015, June 23). Maintaining Accurate \& Systematic Student Records. Retrieved from Study.com: https://study.com/academy/lesson/maintaining-accuratesystematic-student-records.html

[12] Nelsen, J. (n.d.). Positive Discipline for Teenagers: Learn how to be a Great Therapist for your Teen Clients and Their Parents. Retrieved from Positive Discipline: https://www.positivediscipline.com/dr-jane-nelsen

[13] Ofordile. (n.d.). Behaviour Modification (Principles and Applications). Thinkers corner.

[14] OnLine, L. (2002). Motivation: The Key to Academic Success. Retrieved
Reading

Rockets: http://www.readingrockets.org/article/motivation-key-academicsuccess

[15] Podolsky, T. K. (2016, June 03). Does Teaching Experience Increase Teacher Effectiveness? A Review of the Research. Retrieved from Learning policy institute: https://learningpolicyinstitute.org/product/does-teachingexperience-increase-teacher-effectiveness-review-research

[16] Storms, P. (n.d.). The Importance of Clay and Pottery In Child Development. Lakeside Pottery, 45-48.

[17] Tynan, K. (2017, May 15). The Reinforcement Model: Innovative Approaches to eLearning That Increase Confidence and Competence. Retrieved from Core Axis: https://coreaxis.com/thereinforcement-model-elearning/ 